\title{
Entropi Tabanlı Waspas Yöntemiyle Karadeniz Bölgesindeki Şehirlerin Bankacılık Performansının Analizi: 2014-2019 Dönemi
}

DOI: $10.26466 /$ opus. 866120

*

\author{
Arif Cilek * $^{*}$ Alper Karavardar ** \\ * Öğr. Gör., Giresun Üniversitesi, Bulancak Kadir Karabaş UBYO, Giresun/Türkiye \\ E-Posta: arif.cilek@giresun.edu.tr ORCID: 0000-0002-9277-3953 \\ ** Doç.Dr., Giresun Üniversitesi, İktisadi ve İdari Bilimler Fakültesi, Giresun/Türkiye \\ E-Posta: akaravardar@yahoo.com ORCID: 0000-0001-7330-4038
}

Öz

Bankaların, hanehalkının tasarruflarının yatırıma dönüştürülmesinde köprü görevi üstlendiği için, bir ülkenin ekonomisi bakımından çok büyük değeri vardır. Bankaların parasal kazançları çekme, doğrudan kredi ve diğer bankacılık hizmetlerini sunma kabiliyetleri, bir ülkenin gelişmesine, ekonomik büyümesine doğrudan doğruya katkı să̆lar. Bankaların ne ölçüde sağlıklı bir şekilde faaliyetlerini sürdürdüğ̈̈nü kavramak, bankaları birbirleriyle karşılaştırabilmek ve büyümelerini analiz etmek amacıyla banka etkinlik ve başarım sonuçlarından faydalanılır. Bu çalışmada Karadeniz Bölgesi'nde bulunan şehirlerin çok kıstaslı karar verme yöntemlerinden Entropi ve WASPAS yöntemleri kullanılarak şehir bazlı değerlendirilmesi amaçlanmıştır. 2014- 2019 dönemine ait temel bilanço göstergeleri ve istatistiki veriler analiz edilmiştir. Uygulamada kriter olarak toplam krediler, toplam mevduat, çalışan sayısı, şube sayısı ve takip hesaplarındaki krediler oranı kullanılmıştır. Entropi yöntemi kullanılarak kıstasları öncelikleri tespit edilmiştir. Kıstasların öncelikleri tespit edildikten sonra, WASPAS tekniği ile Türkiye'de, Karadeniz Bölgesi'nde yer alan şehirlerin bankacilık performansının sıralaması yapılmıştır. Yapılan analizler vasıtasıyla 2014-2019 dönemi için en iyi performansı gösteren şehrin Samsun, en kötü performansa gösteren şehirlerin Kastamonu ve Tokat olduğu sonucuna varılmıştır.

Anahtar Kelimeler: Banka Performansı, Entropi Yöntemi, WASPAS Yöntemi, Çok Kıstaslı Karar Verme

Jel Kodları: $\quad$ C65, G20, G21 


\title{
Analysis of the Banking Performance of Cities in the Black Sea Region with Entropy-Based Waspas Method: 2014-2019 Period
}

*

\begin{abstract}
Banks are of immense value to a country's economy, as they act as a bridge in converting household savings to investment. The ability of banks to attract monetary gains and to offer direct loans and other banking services directly contributes to the development and economic growth of a country. Bank efficiency and performance results are utilized in order to understand the extent to which banks continue their activities properly, to compare banks with each other and to analyze their growth. In this study, it was aimed to evaluate the cities in the Black Sea Region on a city basis using Entropy and WASPAS methods, which are among the multi-criteria decision-making methods. Basic balance sheet indicators and statistical data for the 2014-2019 period were analyzed. In practice, total loans, total deposits, number of employees, number of branches and ratio of loans in follow-up accounts were used as criteria. The priority of the criteria has been determined by using the entropy method. After determining the priorities of the criteria, with technical WASPAS in Turkey, the Black Sea Region is located in the city of banking performance rankings were made. Based on the analysis conducted, it was concluded that the city with the best performance for the 2014-2019 period was Samsun, and the worst performing cities were Kastamonu and Tokat.
\end{abstract}

Keywords: Bank Performance, Entroph Method, WASPAS Method, Multi Criteria Decision Making

Jel Codes: C65, G20, G21 


\section{Giriş}

Bankaların, hanehalkının tasarruflarının yatırıma dönüştürülmesinde köprü görevi üstlendiği için, bir ülkenin ekonomisi bakımından çok büyük değeri vardır. Bankaların parasal kazançları çekme, doğrudan kredi ve diğer bankacılık hizmetlerini sunma kabiliyetleri, bir ülkenin gelişmesine, ekonomik büyümesine doğrudan doğruya katkı sağlar. Bu bağlamda, bankaların sürdürülebilir karlılık sağlaması, sürdürülebilir büyümeyi elde etmesi, ekonomik büyümeyle olan ilişkisi ve katkısı nedeniyle ekonomik büyüme ve banka karlılığı arasında pozitif korelasyon söz konusudur. Aynı zamanda sağlam bilanço yapısı olan bankalar, ekonomik kriz gibi olumsuz şoklar meydana geldiğinde kırılganlığı da minimize eder (Sarı, 2020, s.101).

Bankaların ne ölçüde sağlıklı bir şekilde faaliyetlerini sürdürdüğünü kavramak, bankaları birbirleriyle karşılaştırabilmek ve büyümelerini analiz etmek amacıyla banka etkinlik ve başarım sonuçlarından faydalanılır. Finansal sistemin içinde, en büyük paya sahip olan bankaların başarılarının ölçülmesi aşağıdaki sebeplerden dolayı önem arz etmektedir (Seçme, Bayrakdaroğlu ve Kahraman, 2009, s.11699).

- Bankacılık sistemi içindeki yerlerini belirleyerek kıyaslama yapmak.

- Banka üst yönetimi ve banka ortakları bakımından bankanın performasını değerlendirmek.

- Kararların hipotezler ya da hisler yardımıyla alınmasının yerine gerçek veriler göre alındığını belirlemek.

- Teşkilatdaki sorunlu bölümlerin belirlenmesi ve bu probleri ortadan kaldırmak için tavsiyeler sunmak.

- Teşkilatın içinde öğrenen organizasyona açık ve rekabet üstünlüğü elde edebilecek bölümleri tespit etmek.

Belirtilen sebeplerden dolayı finansal performansların ölçülmesinde kullanılan nicel ve nitel analiz yöntemleri geliştirilmiş, değerlendirmelerde kullanılmıştır. Banka sektöründe karşılaştırma yapmak için var olan birçok alternatif ve kriterin değerlendirilmesi için Çok Kriterli Karar Verme yöntemleri uygun yöntemlerdir. ÇKKV yöntemleri, birden fazla ve birbirinden bağımsız şekillerde ifade edilen faktörleri ele alarak analiz yapabilmektedir. Çünkü, bankaların performanslarına göre bölge sıralanması ve kıyaslanması birden fazla 
kriter ve bu kriterlerin tamamının dikkate alındığ 1 matematiksel metodlar ile ele alınabilir.

Çalışmada Türkiye'de Karadeniz Bölgesi'nde yer alan şehirlerin bankacılık performanslarının analizin yapılması amaçlanmıştır. Bu bağlamda ilk olarak çok kıstaslı karar verme tekniklerinden olan Entropi tekniği kullanılarak; toplam krediler, toplam mevduat, çalışan sayısı, şube sayısı ve takip hesaplarındaki krediler oranı faktörlerinin ağırlık ölçüleri hesaplanmıştır. Faktörlerin ağırlık ölçüleri hesaplanmasının ardından WASPAS tekniği ile Türkiye'de Karadeniz Bölgesi'nde yer alan şehirlerin bankacılık performansının sırası tayin edilmiştir. Çalışmanın sonraki kısımlarında alanyazın taramasına, tekniğe, bulgulara, sonuç ve önerilere değinilmiştir.

\section{Literatür}

Alanyazın taraması yapıldığında Entropi ve WASPAS tekniklerinin hibrit olarak birlikte uygulandığı çalışmaların çok fazla sayıda olduğu görülmemektedir. Bu bağlamda yöntemlerin ayrı ayrı kullanıldığı ve iki tekniğin birlikte, hibrit olarak uygulanan çalışmalardan erişilebilir konumdakilerin özleri aşağıda art arda düzenlenmiştir.

Zhou, Wang ve Qiu (2008) bankacılık sektörü bakamından entropi tekniğini incelemiştir. Çalışmada, çapraz entropi tekniği kullanılarak kredi riskinin belirlenmesi için Çin mevduat bankaları ele alınmıştır. Fakör olarak satışlar/toplam varlıklar, işletme sermayesi/toplam varlıklar, vergi öncesi kar/toplam varlıklar, dağıtılmamış karlar/toplam varlıklar ve imtiyazlı hisses senetleri ve adi hisse senetleri toplamının borçların değerine oranı analize dahil edilmiş, örneklem olarak da ellibir test etme ve altmışdört öğretme örneklemi değerlendirilmiştir. Bulgularına göre, erken uyarı sinyalleri ölçümünde çapraz entropi tekniği son derece başarılı bir yöntemdir.

Bera ve Park (2008), portföy tercihini entropi tekniği ile incelemişlerdir. Almanya, Kanada, Birleşik Devletler, Japonya, İsviçre, İtalya ve Birleşik Krallık için 1969 senesinin Aralık ayından itibaren 2005 senesinin Temmuz ayına kadar 428 gözlemi çözümlemişlerdir. Tekrardan tasnif edilmiş endeks kazancının ortalama ve varyans, 
kovaryans dizeyinden elde edilen verilerle beraber, çapraz entropi tekniğinden faydalanılmıştır.

Alanyazında entropi tekniğinden yararlanılarak portföy tercihi bakımından değerlendirilen analizleri ise Qin, Li ve Ji (2009), Usta ve Kantar (2011), Huang (2012), Zhang, Liu ve Xu (2012) çalışmalarında gerçekleştirmiştir.

Huag (2012)' ye bakıldığında entropi tekniği, finans alanyazınında yatırım kararlarında yararlanılan, benimsenmiş bir metot konumunu almıştır. Ortaya koyulan çalışmalarda bilhassa portföy tercihi çerçevesinde, entropi iki bakımdan değerlendirilmektedir. Birinçi açıdan portföy karlılı̆̆ının tespit edilmesinde belirsizlik kıstası olarak; ikincisinde ise yatırım çeşitlendirmesinde gerçekleştirilen kapsamıdır. Entropi, geleneksel ortalama varyans paradigmasınının gelişmesini sağlamak amacıyla entropi tekniğinden yararlanılmıştır.

Zhou, Cai ve Tong (2013), entropi metodunun finans çevresindeki yararlanma kapsamını tetkik etmişlerdir. Çalışmalarında, metodun risk düzeyinin belirlenmesinde ve portföy çeşitlendirmesinde olmak amacıyla portföy tercihinde; opsiyon ve öteki türev ürünlerin fiyatlarının tespit edilmesi olmak amaciyla varlık fiyatlandirmasında; ham petrol pazarları ve bankacılık sektörü gibi öteki finans alanlarında yararlanılabileceğini belirtmişlerdir.

Sarıkaya ve Tatlıdil (2013), çalışmalarında Markowitz OrtalamaVaryans paradigması ile minimal entropi ve maksimal entropi ölçütünden yararlanarak BİST Ulusal-30 göstergesinde optimal portföy tercihini analiz etmişlerdir. Ulaşılan analiz sonuçları bakımından ortalama varyans paradigması ve Entropi metotları bakımından benzer kazanç düzeylerinde daha uygun sonuçları bildirmektedir.

WASPAS tekniğinin uygulama alanları finans biliminde oldukça kısıtlıdır. Teknik başta dış kaynaklardan yararlanmada, ağır sanayi ve hafif sanayi ile alakalı verilen kararlarda gibi benzer alanlarda öteki hibrit karar verme metotları ile mukayeseli olarak uygulanmaktadır. Chakraborty ve Zavadskas (2014) ve Chakraborty, Zavadskas ve Antucheviciene (2015), mal ve hizmet üretim proseslerinde meydana gelen sorunların ortadan kaldırılmasında uygulamışlardır.

Ömürbek, Karaatli ve Balci (2016), entropi, SAW (Simple Additive Weighting) ve MAUT (Multi-Attribute Utility Theory) gibi çok kıstaslı 
karar verme teknikleri vasıtasıyla otomotiv sektöründe yer alan, BİST'de payları alınıp satılan işletmelerin finansal başarılarını analiz etmişlerdir. Çalışmalarında net satışlar/personel, sermaye, hisse senedi, personel sayısı, net kar marjı, cari oran, net kar/satışlar, satış geliri, net kar/ sermaye ve piyasa değeri faktörlerinden yararlanılmıştır.

Tunca, Ömürbek, Cömert ve Aksoy (2016), çok kıstaslı karar verme teknikleri vasıtasıyla OPEC' e dahil olan 12 ülkenin başarımlarını analiz etmişlerdir. Doğalgaz ihracatı, petrol ürünleri ihracatı, ham petrol ihracatı, rafine yapılmış petrol üretimi, rafineri kapasitesi, doğalgaz üretimi, ham petrol üretimi, ispatlanmış doğalgaz rezervleri, ispatlanmış ham petrol rezervleri, petrol ihracatının tutarı ve ihracat tutarı kıstaslarını entropi tabanlı MAUT tekniği vasitasıyla değerlendirmişlerdir. Doğalgaz ihracatı, çalışmada Entropi tekniği ile tespit edilen ağırlığı en fazla olan kıstas olarak belirlenmiştir.

Akçakanat, Eren, Aksoy ve Ömürbek (2017), yaptıkları çalışmada bankaları bulundukları ölçeklere göre 2016 yılı için ilk üç çeyrek verilerinden faydalanarak analiz etmişlerdir. Personel sayısı, şube sayısı, toplam özkaynaklar, toplam mevduat, toplam krediler ve alacaklar, toplam aktifler kıstaslarını Entropi vasıtayla önceliklendirmişler, sonrasında ayrı ayrı ölçeklerdeki bankaların sıralamasını WASPAS tekniği vasıtasıyla gerçekleştirmişlerdir.

Ural, Demirali ve Özçalık (2018), Türkiye'de sermayesi kamuya ait bankaların başarımlarını Entropi temelli WASPAS tekniği aracılığıyla incelemişlerdir. Analizde kullanılan veriler 2012-2016 dönemindeki mali tablolardan elde edilmiştir. Analiz sonucunda ulaşılan bulgularda Türkiye Vakıflar Bankası 2012 ve 2013 senelerinde birinci sırada yer almıştır. Diğer yıllarda ise birinci sırada yer alan kamu bankasının Ziraat Bankası olduğu tespit edilmiştir.

Gezen (2019), katılım bankalarının finansal başarımlarını Entropi temelli WASPAS tekniği vasıtasıyla analiz etmişlerdir. Analizde kullanılan veriler 2010-2017 dönemindeki mali tablolardan elde edilmiştir. Analiz sonucunda ulaşılan bulgularda Türkiye Finans Katılım Bankası 2010, 2011, 2012, 2013, 2014 ve 2015 senelerinde siralamanin en üstünde yer alırken, KuveytTürk Katılım Bankası 2016 ve 2017 senelerinde birinci sırada yer almıştır. 
Karavardar ve Çilek (2020), Entropi yöntemini kullanarak banka tercihini belirleyen kriterleri Giresun ili özelinde ağırlıklandırmıştır. Yapılan Entropi analiz sonuçlarına göre banka tercihini belirleyen faktörlerin en önemlisi Şube ve Alternatif Kanal Ağ kriteri olmuş ve onu sırası ile perseonel özellikleri, bankanın fiziki ve teknik yapısı, işlem kolaylığ 1 ve maliyet, hız kriterleri takip etmiştir. En düşük mertebede önemli kıstas ise bankanın güvenilirliği olmuş ve onu ürün ve hizmet çeşitliliği kriteri takip etmiştir.

Alkan ve Albayrak (2020), yaptıkları çalışmada, Entropi tekniğini kullanarak Türkiye'deki yirmialtı bölge göz önünde bulundurularak yenilenemeyen enerji kaynaklarının alternatifi olan yenilenebilir enerji kaynaklarının kıstaslarını ağırlıklandırmışlardır.

Eş ve Kök (2020), Entropi ve WASPAS yöntemini kullanarak 20152019 yılları arasında banka performanlarını analiz etmişlerdir. Analiz sonucunda, WASPAS yöntemine göre 2015 yılında başarı sıralamasının en üstünde yer alan banka Garanti Bankası olmuş, 2016 ve 2017 yıllarında Ziraat Bankası ve 2018-2019 yıllarında Yapı ve Kredi Bankası seçilmiştir.

Karaca, Altemur ve Çevik (2020), mevduat bankalarının finansal başarımlarını Entropi temelli WASPAS tekniği vasıtasıyla analiz etmişlerdir. Yapılan analize 65 finansal rasyo dahil edilmiştir. Entropi tekniği yardımıyla rasyoların önem mertebeleri belirlenerek toplu bir şeklide ve kendi grupları içinde bankaların, WASPAS tekniği bulgularına göre ile sıralamaları gerçekleştirilmiştir.

\section{Yöntem}

Bu çalışmada Türkiye'de Karadeniz Bölgesi'nde yer alan 16 şehrin bankacılık performansları 2014, 2015, 2016, 2017, 2018 ve 2019 yılları için analiz edilerek, şehirlerin ayrı ayrı her bir yıl için performans sıralamasının tespit edilmesi ve sözü edilen yıllar bakımından performansı en yüksek şehrin tespit edilmesi amaçlanmıştır. Bu bağlamda aşağıda detaylı bir şekilde, yararlanılan tekniklere, analizler sonucunda ulaşılan bulgulara yer verilmiştir. 


\section{Araştırmanın Yöntemi}

Karadeniz Bölgesi'nde yer alan 16 şehrin bankacılık başarım sırasını tespit etmek amaciyla ilk olarak kıstasların önem derecelerini belirlemek için Entropi tekniği, ikinci aşamada ise sıralamayı belirlemek için WASPAS tekniğinden yararlanılmıştır. Entropi tekniği ve WASPAS tekniği ile ilgili açıklamalar aşağıda yer almaktadır.

\section{Entropi Yöntemi}

Entropi terimi Rudolph Clausius (1865) aracılığıyla ilk defa alanyazına girmiştir. Bir sistemdeki intizamsızlığın ve belirsizliğin bir boyutu olarak açıklanmıştır (H. Zhang, C. Gu, L. Gu ve Y. Zhang, 2011, s.444). Bugün ilk önce fizik bilimi, sonrasında matematik ve mühendislik bilimlerinde oldukça benimsenmiş bir biçimde kullanılan Entropi terimi Shannon (1948) aracılığıyla enformasyon kuramına tatbik edilmiştir. Mevcut veri setinin temin ettiği yararlı bilginin ölçüsünü belirlemek için Entropi tekniği kullanılmaktadır (Wu, Sun, Liang, ve Zha, 2011, s.5163). Tekniğin en stratejik niteliği tek veri grubundan, bütüne kadar farklı ölçeklerde yararlanma imkanının olmasıdır. Ayrıca teknik estetik ölçmede uygulanabilen az sayıdaki objektif analiz tekniklerinin içerisinde yerini almaktadır. Teknik, yapı biçimleriyle ilgili bilgilerin de analizini gerçekleştirmektedir (Bostancı ve Ocakçı, 2009, s.31).

Entropi tekniği 5 basamaktan meydana gelmektedir (Karami ve Johansson, 2014, s.523-524; Wang ve Lee, 2009, s.8982).

Adım 1: Karar dizeyinde birbirinden ayrı indeks kapsamının eş ölçülemezlik üstündeki gücünü ortadan kaldırmak için indeksler farklı tekniklerle tek tip haline getirilebilmektedir. Denklem (1) ve denklem (2) vasitasıyla maliyet ve fayda indeksleri bakımından kistaslar normalizasyon hesaplamalarıyla standartlaştırılmaktadır.

$\begin{array}{ll}P_{i j}=\frac{x_{i j}-x_{j}^{\min }}{x_{j}^{\max }-x_{j}^{\min }} & (\mathrm{i}=1,2,3, \ldots, \mathrm{m} \text { ve } \mathrm{j}=1,2,3, \ldots, \mathrm{n}) \\ P_{i j}=\frac{x_{j}^{\max }-x_{i j}}{x_{j}^{\max }-x_{j}^{\min }} & (\mathrm{i}=1,2,3, \ldots, \mathrm{m} \text { ve } \mathrm{j}=1,2,3, \ldots, \mathrm{n})\end{array}$ 
Adım 2: Değişik ölçü ünitelerindeki karşıtlıkları ortadan kaldırmak amacıyla normalizasyon gerçekleştirilerek $P_{i j}$ elde edilir.

$$
\begin{aligned}
& P_{i j}=\frac{r_{i j}}{\sum_{i=1}^{m} r_{i j}} \\
& i: \text { alternatifler, }
\end{aligned}
$$

$j:$ kriterler,

$P_{i j}:$ normalize edilmiş değerler,

$r_{i j}$ : verilen fayda değeri

Adım 3: Denklem (4) vasitasıyla $E_{j}$ 'nin entropisi elde edilir.

$$
\begin{aligned}
& E_{j}=-k \sum_{i=1}^{m} P_{i j} \ln \left(P_{i j}\right) \quad(\mathrm{i}=1,2,3, \ldots, \mathrm{m} \text { ve } \mathrm{j}=1,2,3, \ldots, \mathrm{n}) \\
& k:(\ln (\mathrm{n}))^{-1} \\
& \mathrm{k}: \text { entropi katsayısı } \\
& E_{j}: \text { entropi değeri } \\
& P_{i j}: \text { normalize edilmiş değerler }
\end{aligned}
$$

Adım 4: Bu aşamada ise $d j$ belirsizliği denklem (5) vasıtasıyla bulunur.

$$
d j=1-E j ; \forall j
$$

Adım 5: Denklem (6) vasıtasıyla j faktörünün önem mertebesi değeri olarak $w_{j}$ öncelik yüzdesi tespit edilir.

$$
W_{j}=\frac{d_{j}}{\sum_{j=1}^{n} d_{j}}, \forall_{j}
$$

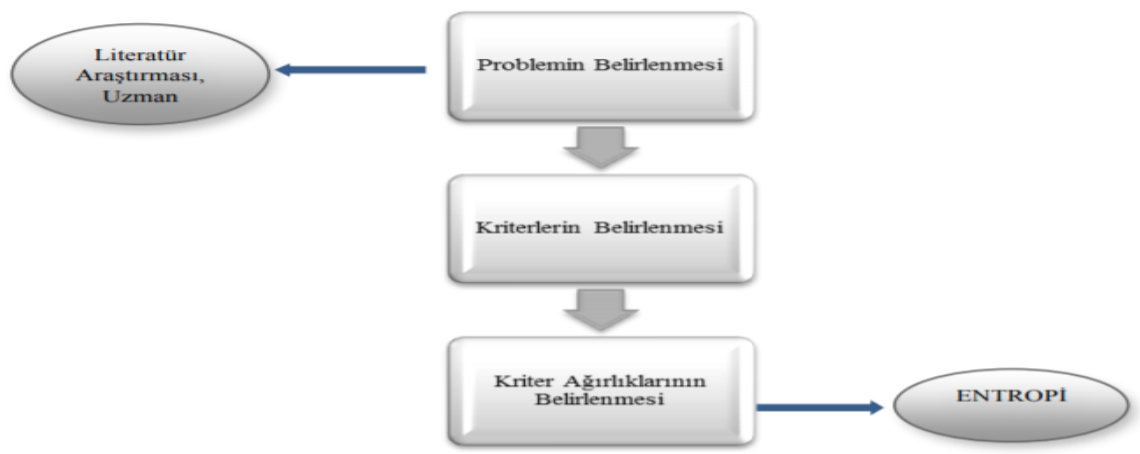

Şekil 1. Entropi Uygulama Adımlanı (Kaynak: Memiş, 2019, s.660) 


\section{WASPAS Yöntemi}

2012 senesinde Zavadskas ve arkadaşları tarafınca WASPAS tekniği (Weighted Aggregated Sum Product Assesment) tavsiye edilmiştir (Madić, Gecevska, Radovanović ve Petković, 2014, s.80). Bu tekniğin geliştirilmesi; Ağırlıklı Toplam Modeli olan WSM (Weighted Sum Model) ve Ağırlıklı Ürün Modeli olan WPM'nin (Weighted Product Model) birleştirilmesiyle sağlanmıştır. En elverişli ÇKKV tekniği olarak tavsiye edilen WASPAS tekniği, doğruya dayanarak ya da doğru olduğunu gerçekleştirmek için iki ayrı teknikten birlikte yararlanan yeni bir tekniktir. Bu bağlamda tekniğin amacı, kıstasların sıralamasının doğruluğunun derecesini yükseltmektir (Zavadskas, Antucheviciene, Saparauskas ve Turskis, 2013, s.3).

Bulgularının tutarlılı̆̆ halen sorgulanabilen birtakım çok kıstaslı karar verme teknikleri bulunmaktadır. Tek bir teknikten yararlanılmasına nazaran, iki ya da daha çok sayıda farklı çok kıstaslı optimizasyon tekniklerinden yararlanılması, koşulları ya da güvenilirliğine göre, daha tutarlı analizlerin yapılmasını sağlayacaktır (Brauers ve Zavadskas, 2012, s.4). Aşamaları aşağıdaki şekilde sıralanan WASPAS tekniği, 6 basamaktan oluşmaktadır (Chakraborty ve Zavadskas, 2014, s.2-3; Zavadskas, Turskis, Antucheviciene ve Zakarevicius, 2012, s.3).

Basamak 1: Karar Dizeyinin Meydana Getirilmesi: WASPAS tekniği birinci basamakta aşadaki dizeye benzer şekilde karar/değerlendirme dizeyi ile başlamaktadır.

$$
X_{m x n}=\begin{array}{cccc}
x_{11} & x_{12} & \ldots & x_{1 \mathrm{n}} \\
x_{21} & x_{22} & \ldots & x_{1 \mathrm{n}} \\
\vdots & \vdots & \ldots & \vdots \\
x_{m 1} & x_{m 1} & \ldots & x_{m n}
\end{array}
$$

Bu dizeyde; $m$ aday alternatiflerinin, $n$ ise değerlendirme kıstaslarının sayısını işaret etmektedir. $X_{i j}$, $j^{\prime}$ inci kıstas göz önüne alınarak i'inci alternatifin performansıdır. 
Basamak 2: Normalize Duruma Getirilmiş Karar Dizeyinin Meydana Getirilmesi: Aşağıdaki yer alan iki eşitlikten yararlanarak doğrusal normalizasyon işlemi gerçekleştirilmektedir.

Fayda kriterleri için kullanılacak olan denklem;

$\bar{x}_{i j}=\frac{x_{i j}}{\max _{i j} \cdot x_{i j}}$

Maliyet kriterleri için ise;

$\bar{x}_{i j}=\frac{\min _{i j} \cdot x_{i j}}{x_{i j}}$

Bu eşitliklerde yer alan $\bar{x}_{i j}$ ölçüsü, $x_{i j}$ ölçüsünün normalize duruma getirilmiş halidir.

Basamak 3: Ağırlılı Toplam Tekniğine (WSM) Göre i Alternatifinin Toplam Göreceli Öneminin Bulunması: WASPAS tekniğinde, iki eşitlik kıstası esas alınarak, bir eşzamanlı, optimizm faktörü bulmaya çalışılmaktadır. Toplam göreceli ölçü ağırlığı, $\boldsymbol{i}$ 'inci alternatif ölçüsü ayrı ayrı her faktöre ait ağırlık ölçüsüyle çarpılır ve sonrasında ayrı ayrı her alternatif ölçüsü sırasıyla toplanarak aşağıdaki eşitlik (10) vasıtasıyla bulunur.

$\mathrm{Q}_{i}{ }^{(1)}=\sum_{j=1}^{n} \bar{x}_{i j} \cdot w_{j}$

Basamak 4: Ağırlıklı Ürün Tekniğine (WPM) Göre i Alternatifinin Toplam Göreceli Ă̆̊rlı̆̆ııın Bulunması: Bu basamakta WPM tekniğine dayalı toplam göreceli ağırlık ölçüleri aşağıdaki eşitlik vasıtasıyla bulunur. Normalizasyon işlemi yapılmış karar dizeyi üstünden ayrı ayrı her $\boldsymbol{i}$ alternatif faktörün ölçüsünü hesaplamak için faktör ağırlığının üssü alınır ve ulaşılan değerler ayrı ayrı her alternatif için sırayla çarpılarak $\mathrm{Q}_{i}^{(2)}$ ölçüsü elde edilir.

$\mathrm{Q}_{i}^{(2)}=\prod_{j=1}^{n}\left(\bar{x}_{i j}\right)^{w j}$

Basamak 5: Toplamsal ve Çarpımsal Tekniklerin Önceliklendirilmiş Ortak Genel Faktör Ölçüsünün Bulunması: Toplamsal ve çarpımsal tekniklerin önceliklendirilmiş ortak genelleştirilmiş faktör ölçüleri aşağıda eşitlik (12) vasıtasıyla hesaplanmaktadır.

$Q_{i}=0,5 Q_{i}^{(1)}+0,5 Q_{i}^{(2)}=0,5 \sum_{j=1}^{n} \bar{x}_{i j} \cdot w_{i}+0,5 \prod_{j=1}^{n}\left(\bar{x}_{i j}\right)^{w j}$ 
Basamak 6: Alternatif Genel Toplam Göreceli Ă̆ırlı̆̆ının Bulunması: Karar verme prosesinin oluşturulmasında, doğruluğu ve etkinliği yükseltmek için WASPAS tekniğinde ayrı ayrı her alternatifin toplam göreceli ağırlığını tespit etmek için daha genel bir eşitlik aşağıdaki biçimde oluşturulmuştur.

$Q_{i}=\lambda 0,5 Q_{i}^{(1)}+(1-\lambda) Q_{i}^{(2)}=(\lambda) \sum_{j=1}^{n} \bar{x}_{i j} \cdot w \mathrm{i}+(1-\lambda) \prod_{j=1}^{n}\left(\bar{x}_{i j}\right)^{w j}$ (13)

$$
(\lambda-0,0.1, \ldots 1) \text {. }
$$

Tayin edilen alternatifler $\mathrm{Q}$ ölçüsüne göre önceliklendirilir. $\mathrm{Bu}$ bağlamda en önemli alternatif, $Q$ ölçüsünün bulundurduğu en yüksek değer olan alternatifdir. $\lambda=0$ olduğu durumda WASPAS tekniği WPM'ye çevrilir, $\lambda=1$ olduğu durumda da WSM tekniğine çevrilir.

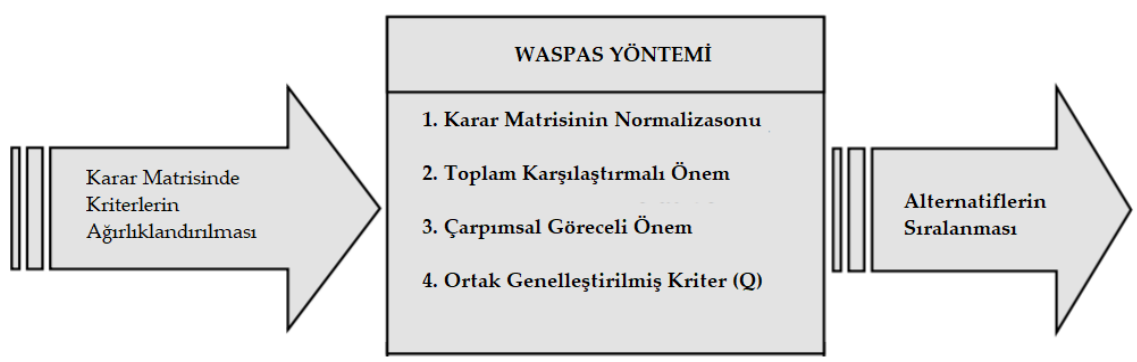

Şekil 2. Waspas Uygulama Adımlan (Kaynak: Alinezhad ve Khalili, 2019, s.98)

\section{Bulgular}

Bu çalışmada Karadeniz Bölgesi'nde bulunan şehirlerin 2014-2019 yılları arasındaki bankacılık performansının değerlendirilmesinde kullanılan kriterler; toplam krediler, toplam mevduat, çalışan sayısı, şube sayısı ve takip hesaplarındaki krediler oranı faktörler olarak tespit edilmiştir. Tespit edilen bu faktörlerin ağırlıklarının tayin edilmesinde Entropi tekniğinden yararlanılmış ve sonrasında bölgede yer alan 16 şehrin performans sıralaması WASPAS tekniği ile gerçekleşmiştir.

Tespit edilen faktörlere göre Karadeniz Bölgesi'nde yer alan 16 şehrin 2014, 2015, 2016, 2017, 2018 ve 2019 senelerine ait bankacilık verileri aşağıda Tablo 1.'de yer almaktadır. 
Tablo 1. Karadeniz Bölgesin'deki Şehirlerin Bankacılık Verileri (2014-2019)

\begin{tabular}{|c|c|c|c|c|c|c|}
\hline İl & Yillar & $\begin{array}{l}\text { Toplam } \\
\text { Kredi }\end{array}$ & $\begin{array}{l}\text { Toplam } \\
\text { Mevduat }\end{array}$ & $\begin{array}{l}\text { Çalışan } \\
\text { Sayısı }\end{array}$ & $\begin{array}{l}\text { Şube } \\
\text { Sayısı }\end{array}$ & $\begin{array}{l}\text { Takipteki Krediler } \\
\text { Oranı }\end{array}$ \\
\hline Amasya & 2014 & 2.616 & 1.347 & 469 & 41 & 2,68 \\
\hline Artvin & 2014 & 1.292 & 829 & 327 & 35 & 2,62 \\
\hline Bartın & 2014 & 1.199 & 1.293 & 260 & 22 & 3,80 \\
\hline Çankırı & 2014 & 1.272 & 720 & 252 & 26 & 1,70 \\
\hline Çorum & 2014 & 4.170 & 2.586 & 754 & 65 & 2,90 \\
\hline Giresun & 2014 & 2.744 & 2.328 & 575 & 50 & 4,00 \\
\hline Gümüşhane & 2014 & 669 & 407 & 161 & 19 & 2,61 \\
\hline Karabük & 2014 & 2.482 & 1.254 & 369 & 31 & 2,09 \\
\hline Kastomonu & 2014 & 2.478 & 1.530 & 586 & 53 & 3,56 \\
\hline Ordu & 2014 & 4.329 & 2.696 & 815 & 69 & 2,87 \\
\hline Rize & 2014 & 2.955 & 1.520 & 514 & 51 & 1,63 \\
\hline Samsun & 2014 & 10.426 & 6.713 & 2.690 & 140 & 3,32 \\
\hline Sinop & 2014 & 1.407 & 1.197 & 277 & 27 & 2,58 \\
\hline Tokat & 2014 & 3.479 & 1.618 & 671 & 64 & 4,34 \\
\hline Trabzon & 2014 & 6.980 & 5.017 & 1.617 & 113 & 2,55 \\
\hline Zonguldak & 2014 & 4.131 & 5.206 & 938 & 69 & 5,20 \\
\hline Amasya & 2015 & 2.932 & 1.538 & 480 & 43 & 3,06 \\
\hline Artvin & 2015 & 1.431 & 1.041 & 329 & 34 & 2,61 \\
\hline Bartın & 2015 & 1.316 & 1.479 & 262 & 22 & 4,24 \\
\hline Çankırı & 2015 & 1.468 & 814 & 262 & 27 & 1,85 \\
\hline Çorum & 2015 & 4.937 & 2.940 & 760 & 65 & 3,09 \\
\hline Giresun & 2015 & 3.115 & 2.760 & 588 & 52 & 4,14 \\
\hline Gümüşhane & 2015 & 760 & 504 & 157 & 18 & 1,79 \\
\hline Karabük & 2015 & 2.858 & 1.557 & 365 & 29 & 2,49 \\
\hline Kastomonu & 2015 & 2.838 & 1.890 & 612 & 55 & 3,55 \\
\hline Ordu & 2015 & 4.649 & 3.331 & 847 & 70 & 3,40 \\
\hline Rize & 2015 & 3.196 & 1.842 & 502 & 52 & 2,45 \\
\hline Samsun & 2015 & 11.283 & 7.867 & 2.691 & 142 & 4,28 \\
\hline Sinop & 2015 & 1.463 & 1.384 & 287 & 28 & 2,70 \\
\hline Tokat & 2015 & 3.821 & 1.963 & 678 & 66 & 5,00 \\
\hline Trabzon & 2015 & 7.539 & 6.434 & 1.616 & 114 & 3,45 \\
\hline Zonguldak & 2015 & 4.483 & 5.958 & 936 & 69 & 5,72 \\
\hline Amasya & 2016 & 3.162 & 1.854 & 461 & 41 & 4,57 \\
\hline Artvin & 2016 & 1.580 & 1.210 & 320 & 34 & 3,63 \\
\hline Bartın & 2016 & 1.430 & 1.745 & 253 & 21 & 4,67 \\
\hline Çankırı & 2016 & 1.782 & 943 & 250 & 27 & 2,23 \\
\hline Çorum & 2016 & 5.605 & 3.344 & 742 & 61 & 3,99 \\
\hline Giresun & 2016 & 3.648 & 3.262 & 571 & 52 & 3,71 \\
\hline Gümüşhane & 2016 & 867 & 590 & 144 & 18 & 1,95 \\
\hline Karabük & 2016 & 3.160 & 1.648 & 360 & 29 & 2,61 \\
\hline Kastomonu & 2016 & 3.096 & 2.094 & 586 & 54 & 3,63 \\
\hline Ordu & 2016 & 5.347 & 3.809 & 837 & 67 & 3,33 \\
\hline Rize & 2016 & 4.009 & 2.226 & 495 & 50 & 2,52 \\
\hline Samsun & 2016 & 12.333 & 9.354 & 2.726 & 142 & 5,74 \\
\hline Sinop & 2016 & 1.584 & 1.628 & 288 & 28 & 3,82 \\
\hline Tokat & 2016 & 4.087 & 2.331 & 645 & 63 & 5,73 \\
\hline Trabzon & 2016 & 8.817 & 7.601 & 1.593 & 111 & 3,59 \\
\hline Zonguldak & 2016 & 4.780 & 6.695 & 914 & 67 & 6,28 \\
\hline Amasya & 2017 & 3.788 & 2.252 & 456 & 39 & 4,29 \\
\hline Artvin & 2017 & 1.968 & 1.436 & 316 & 34 & 3,28 \\
\hline
\end{tabular}




\begin{tabular}{|c|c|c|c|c|c|c|}
\hline Bartın & 2017 & 1.828 & 2.057 & 239 & 21 & 4,30 \\
\hline Çankırı & 2017 & 2.356 & 1.104 & 246 & 27 & 2,03 \\
\hline Çorum & 2017 & 6.897 & 3.893 & 731 & 59 & 3,45 \\
\hline Giresun & 2017 & 4.476 & 3.855 & 560 & 52 & 3,05 \\
\hline Gümüşhane & 2017 & 1.058 & 729 & 141 & 18 & 1,58 \\
\hline Karabük & 2017 & 3.168 & 2.612 & 356 & 27 & 2,47 \\
\hline Kastomonu & 2017 & 3.858 & 2.516 & 567 & 51 & 2,89 \\
\hline Ordu & 2017 & 6.814 & 4.713 & 827 & 66 & 2,55 \\
\hline Rize & 2017 & 4.715 & 2.848 & 497 & 49 & 2,08 \\
\hline Samsun & 2017 & 15.868 & 11.481 & 2.746 & 138 & 4,42 \\
\hline Sinop & 2017 & 1.998 & 1.975 & 278 & 28 & 3,43 \\
\hline Tokat & 2017 & 4.920 & 2.778 & 633 & 57 & 4,63 \\
\hline Trabzon & 2017 & 10.915 & 9.225 & 1.537 & 108 & 2,89 \\
\hline Zonguldak & 2017 & 5.924 & 7.998 & 874 & 66 & 5,11 \\
\hline Amasya & 2018 & 3.937 & 2.529 & 451 & 40 & 5,02 \\
\hline Artvin & 2018 & 2.097 & 1.647 & 326 & 34 & 3,82 \\
\hline Bartın & 2018 & 1.977 & 2.463 & 242 & 21 & 4,11 \\
\hline Çankırı & 2018 & 2.925 & 1.278 & 254 & 28 & 2,87 \\
\hline Çorum & 2018 & 7.572 & 4.709 & 741 & 60 & 4,29 \\
\hline Giresun & 2018 & 5.003 & 4.608 & 580 & 53 & 4,28 \\
\hline Gümüşhane & 2018 & 1.170 & 845 & 153 & 19 & 1,76 \\
\hline Karabük & 2018 & 3.492 & 2.654 & 340 & 27 & 2,65 \\
\hline Kastomonu & 2018 & 4.201 & 2.927 & 573 & 51 & 3,20 \\
\hline Ordu & 2018 & 7.177 & 5.711 & 820 & 67 & 3,16 \\
\hline Rize & 2018 & 5.405 & 3.102 & 490 & 48 & 2,19 \\
\hline Samsun & 2018 & 15.953 & 13.154 & 2.664 & 139 & 4,91 \\
\hline Sinop & 2018 & 2.197 & 2.430 & 287 & 30 & 3,41 \\
\hline Tokat & 2018 & 5.158 & 3.215 & 637 & 57 & 5,16 \\
\hline Trabzon & 2018 & 11.946 & 11.203 & 1.519 & 107 & 3,42 \\
\hline Zonguldak & 2018 & 6.091 & 9.629 & 863 & 65 & 5,94 \\
\hline Amasya & 2019 & 4.401 & 3.208 & 444 & 38 & 5,00 \\
\hline Artvin & 2019 & 2.380 & 2.081 & 311 & 33 & 4,79 \\
\hline Bartın & 2019 & 2.111 & 3.087 & 234 & 21 & 6,71 \\
\hline Çankırı & 2019 & 3.481 & 1.761 & 253 & 28 & 3,51 \\
\hline Çorum & 2019 & 8.200 & 5.891 & 713 & 59 & 4,90 \\
\hline Giresun & 2019 & 5.517 & 5.772 & 565 & 52 & 4,82 \\
\hline Gümüşhane & 2019 & 1.309 & 970 & 148 & 19 & 3,45 \\
\hline Karabük & 2019 & 3.995 & 3.140 & 329 & 26 & 3,39 \\
\hline Kastomonu & 2019 & 4.561 & 3.799 & 571 & 50 & 3,68 \\
\hline Ordu & 2019 & 8.304 & 7.346 & 819 & 67 & 4,10 \\
\hline Rize & 2019 & 7.078 & 4.322 & 481 & 47 & 2,48 \\
\hline Samsun & 2019 & 18.223 & 16.703 & 2.576 & 134 & 5,21 \\
\hline Sinop & 2019 & 2.541 & 2.972 & 282 & 30 & 3,89 \\
\hline Tokat & 2019 & 5.869 & 4.102 & 621 & 56 & 5,47 \\
\hline Trabzon & 2019 & 13.341 & 14.049 & 1.516 & 106 & 3,90 \\
\hline Zonguldak & 2019 & 6.826 & 11.583 & 846 & 64 & 6,00 \\
\hline
\end{tabular}

Kaynak: Türkiye Bankalar Birliği'nin internet sayfasından alınarak hazırlanmıştır. (www.tbb.org.tr)

Karadeniz Bölgesi'nde yer alan 16 şehrin 2014, 2015, 2016, 2017, 2018 ve 2019 senelerine ait bankacılık verileri fayda maliyet bileşenleri dikkate alınarak tercih edilen ayrı ayrı faktör ölçüsünün yer aldığı senenin 
toplamina bölünmesiyle elde edilen Entropi tekniği aracılığıyla normalize hale getirilmiş karar dizeyi aşağıda Tablo 2.'de yer almaktadır.

Tablo 2. Entropi Tekniği ile Normalize Duruma Getirilmiş Karar Dizeyi

\begin{tabular}{|c|c|c|c|c|c|c|}
\hline İl & Yillar & $\begin{array}{l}\text { Toplam } \\
\text { Kredi }\end{array}$ & $\begin{array}{l}\text { Toplam } \\
\text { Mevduat }\end{array}$ & $\begin{array}{l}\text { Çalışan } \\
\text { Sayısı }\end{array}$ & Şube Sayısı & $\begin{array}{l}\text { Takipteki } \\
\text { Krediler Oranı }\end{array}$ \\
\hline Amasya & 2014 & 0,050 & 0,037 & 0,042 & 0,047 & 0,055 \\
\hline Artvin & 2014 & 0,025 & 0,023 & 0,029 & 0,040 & 0,054 \\
\hline Bartın & 2014 & 0,023 & 0,036 & 0,023 & 0,025 & 0,078 \\
\hline Çankırı & 2014 & 0,024 & 0,020 & 0,022 & 0,030 & 0,035 \\
\hline Çorum & 2014 & 0,079 & 0,071 & 0,067 & 0,074 & 0,060 \\
\hline Giresun & 2014 & 0,052 & 0,064 & 0,051 & 0,057 & 0,083 \\
\hline Gümüşhane & 2014 & 0,013 & 0,011 & 0,014 & 0,022 & 0,054 \\
\hline Karabük & 2014 & 0,047 & 0,035 & 0,033 & 0,035 & 0,043 \\
\hline Kastomonu & 2014 & 0,047 & 0,042 & 0,052 & 0,061 & 0,073 \\
\hline Ordu & 2014 & 0,082 & 0,074 & 0,072 & 0,079 & 0,059 \\
\hline Rize & 2014 & 0,056 & 0,042 & 0,046 & 0,058 & 0,034 \\
\hline Samsun & 2014 & 0,198 & 0,185 & 0,239 & 0,160 & 0,069 \\
\hline Sinop & 2014 & 0,027 & 0,033 & 0,025 & 0,031 & 0,053 \\
\hline Tokat & 2014 & 0,066 & 0,045 & 0,060 & 0,073 & 0,090 \\
\hline Trabzon & 2014 & 0,133 & 0,138 & 0,143 & 0,129 & 0,053 \\
\hline Zonguldak & 2014 & 0,078 & 0,144 & 0,083 & 0,079 & 0,107 \\
\hline Amasya & 2015 & 0,050 & 0,036 & 0,042 & 0,049 & 0,057 \\
\hline Artvin & 2015 & 0,025 & 0,024 & 0,029 & 0,038 & 0,048 \\
\hline Bartın & 2015 & 0,023 & 0,034 & 0,023 & 0,025 & 0,079 \\
\hline Çankırı & 2015 & 0,025 & 0,019 & 0,023 & 0,030 & 0,034 \\
\hline Çorum & 2015 & 0,085 & 0,068 & 0,067 & 0,073 & 0,057 \\
\hline Giresun & 2015 & 0,054 & 0,064 & 0,052 & 0,059 & 0,077 \\
\hline Gümüşhane & 2015 & 0,013 & 0,012 & 0,014 & 0,020 & 0,033 \\
\hline Karabük & 2015 & 0,049 & 0,036 & 0,032 & 0,033 & 0,046 \\
\hline Kastomonu & 2015 & 0,049 & 0,044 & 0,054 & 0,062 & 0,066 \\
\hline Ordu & 2015 & 0,080 & 0,077 & 0,074 & 0,079 & 0,063 \\
\hline Rize & 2015 & 0,055 & 0,043 & 0,044 & 0,059 & 0,046 \\
\hline Samsun & 2015 & 0,194 & 0,182 & 0,237 & 0,160 & 0,080 \\
\hline Sinop & 2015 & 0,025 & 0,032 & 0,025 & 0,032 & 0,050 \\
\hline Tokat & 2015 & 0,066 & 0,045 & 0,060 & 0,074 & 0,093 \\
\hline Trabzon & 2015 & 0,130 & 0,149 & 0,142 & 0,129 & 0,064 \\
\hline Zonguldak & 2015 & 0,077 & 0,138 & 0,082 & 0,078 & 0,106 \\
\hline Amasya & 2016 & 0,0484 & 0,0368 & 0,0412 & 0,0474 & 0,0737 \\
\hline Artvin & 2016 & 0,0242 & 0,0240 & 0,0286 & 0,0393 & 0,0585 \\
\hline Bartın & 2016 & 0,0219 & 0,0347 & 0,0226 & 0,0243 & 0,0753 \\
\hline Çankırı & 2016 & 0,0273 & 0,0187 & 0,0224 & 0,0312 & 0,0360 \\
\hline Çorum & 2016 & 0,0859 & 0,0664 & 0,0663 & 0,0705 & 0,0644 \\
\hline Giresun & 2016 & 0,0559 & 0,0648 & 0,0511 & 0,0601 & 0,0598 \\
\hline Gümüşhane & 2016 & 0,0133 & 0,0117 & 0,0129 & 0,0208 & 0,0315 \\
\hline Karabük & 2016 & 0,0484 & 0,0327 & 0,0322 & 0,0335 & 0,0421 \\
\hline Kastomonu & 2016 & 0,0474 & 0,0416 & 0,0524 & 0,0624 & 0,0585 \\
\hline Ordu & 2016 & 0,0819 & 0,0757 & 0,0748 & 0,0775 & 0,0537 \\
\hline Rize & 2016 & 0,0614 & 0,0442 & 0,0443 & 0,0578 & 0,0406 \\
\hline Samsun & 2016 & 0,1889 & 0,1858 & 0,2437 & 0,1642 & 0,0926 \\
\hline Sinop & 2016 & 0,0243 & 0,0323 & 0,0257 & 0,0324 & 0,0616 \\
\hline
\end{tabular}


Arif Çilek - Alper Karavardar

\begin{tabular}{|c|c|c|c|c|c|c|}
\hline Tokat & 2016 & 0,0626 & 0,0463 & 0,0577 & 0,0728 & 0,0924 \\
\hline Trabzon & 2016 & 0,1350 & 0,1510 & 0,1424 & 0,1283 & 0,0579 \\
\hline Zonguldak & 2016 & 0,0732 & 0,1330 & 0,0817 & 0,0775 & 0,1013 \\
\hline Amasya & 2017 & 0,0470 & 0,0366 & 0,0414 & 0,0464 & 0,0818 \\
\hline Artvin & 2017 & 0,0244 & 0,0234 & 0,0287 & 0,0405 & 0,0625 \\
\hline Bartın & 2017 & 0,0227 & 0,0335 & 0,0217 & 0,0250 & 0,0820 \\
\hline Çankırı & 2017 & 0,0293 & 0,0180 & 0,0224 & 0,0321 & 0,0387 \\
\hline Çorum & 2017 & 0,0856 & 0,0633 & 0,0664 & 0,0702 & 0,0658 \\
\hline Giresun & 2017 & 0,0556 & 0,0627 & 0,0509 & 0,0619 & 0,0582 \\
\hline Gümüşhane & 2017 & 0,0131 & 0,0119 & 0,0128 & 0,0214 & 0,0301 \\
\hline Karabük & 2017 & 0,0393 & 0,0425 & 0,0324 & 0,0321 & 0,0471 \\
\hline Kastomonu & 2017 & 0,0479 & 0,0409 & 0,0515 & 0,0607 & 0,0551 \\
\hline Ordu & 2017 & 0,0846 & 0,0767 & 0,0752 & 0,0786 & 0,0486 \\
\hline Rize & 2017 & 0,0585 & 0,0463 & 0,0452 & 0,0583 & 0,0397 \\
\hline Samsun & 2017 & 0,1970 & 0,1868 & 0,2495 & 0,1643 & 0,0843 \\
\hline Sinop & 2017 & 0,0248 & 0,0321 & 0,0253 & 0,0333 & 0,0654 \\
\hline Tokat & 2017 & 0,0611 & 0,0452 & 0,0575 & 0,0679 & 0,0883 \\
\hline Trabzon & 2017 & 0,1355 & 0,1501 & 0,1397 & 0,1286 & 0,0551 \\
\hline Zonguldak & 2017 & 0,0735 & 0,1301 & 0,0794 & 0,0786 & 0,0974 \\
\hline Amasya & 2018 & 0,0748 & 0,0697 & 0,0400 & 0,0457 & 0,1036 \\
\hline Artvin & 2018 & 0,0398 & 0,0454 & 0,0289 & 0,0389 & 0,0788 \\
\hline Bartın & 2018 & 0,0376 & 0,0679 & 0,0215 & 0,0240 & 0,0848 \\
\hline Çankırı & 2018 & 0,0556 & 0,0352 & 0,0225 & 0,0320 & 0,0592 \\
\hline Çorum & 2018 & 0,1439 & 0,1299 & 0,0657 & 0,0686 & 0,0885 \\
\hline Giresun & 2018 & 0,0951 & 0,1271 & 0,0514 & 0,0606 & 0,0883 \\
\hline Gümüşhane & 2018 & 0,0222 & 0,0233 & 0,0136 & 0,0217 & 0,0363 \\
\hline Karabük & 2018 & 0,0663 & 0,0732 & 0,0302 & 0,0309 & 0,0547 \\
\hline Kastomonu & 2018 & 0,0798 & 0,0807 & 0,0508 & 0,0583 & 0,0660 \\
\hline Ordu & 2018 & 0,1364 & 0,1575 & 0,0727 & 0,0766 & 0,0652 \\
\hline Rize & 2018 & 0,1027 & 0,0855 & 0,0435 & 0,0549 & 0,0452 \\
\hline Samsun & 2018 & 0,3031 & 0,3628 & 0,2363 & 0,1589 & 0,1013 \\
\hline Sinop & 2018 & 0,0417 & 0,0670 & 0,0255 & 0,0343 & 0,0704 \\
\hline Tokat & 2018 & 0,0980 & 0,0887 & 0,0565 & 0,0651 & 0,1065 \\
\hline Trabzon & 2018 & 0,2270 & 0,3090 & 0,1347 & 0,1223 & 0,0706 \\
\hline Zonguldak & 2018 & 0,1157 & 0,2656 & 0,0765 & 0,0743 & 0,1226 \\
\hline Amasya & 2019 & 0,0448 & 0,0353 & 0,0415 & 0,0458 & 0,0701 \\
\hline Artvin & 2019 & 0,0243 & 0,0229 & 0,0290 & 0,0398 & 0,0672 \\
\hline Bartın & 2019 & 0,0215 & 0,0340 & 0,0219 & 0,0253 & 0,0941 \\
\hline Çankırı & 2019 & 0,0355 & 0,0194 & 0,0236 & 0,0337 & 0,0492 \\
\hline Çorum & 2019 & 0,0836 & 0,0649 & 0,0666 & 0,0711 & 0,0687 \\
\hline Giresun & 2019 & 0,0562 & 0,0636 & 0,0528 & 0,0627 & 0,0676 \\
\hline Gümüşhane & 2019 & 0,0133 & 0,0107 & 0,0138 & 0,0229 & 0,0484 \\
\hline Karabük & 2019 & 0,0407 & 0,0346 & 0,0307 & 0,0313 & 0,0475 \\
\hline Kastomonu & 2019 & 0,0465 & 0,0418 & 0,0533 & 0,0602 & 0,0516 \\
\hline Ordu & 2019 & 0,0846 & 0,0809 & 0,0765 & 0,0807 & 0,0575 \\
\hline Rize & 2019 & 0,0721 & 0,0476 & 0,0449 & 0,0566 & 0,0348 \\
\hline Samsun & 2019 & 0,1857 & 0,1840 & 0,2405 & 0,1614 & 0,0731 \\
\hline Sinop & 2019 & 0,0259 & 0,0327 & 0,0263 & 0,0361 & 0,0546 \\
\hline Tokat & 2019 & 0,0598 & 0,0452 & 0,0580 & 0,0675 & 0,0767 \\
\hline Trabzon & 2019 & 0,1359 & 0,1547 & 0,1416 & 0,1277 & 0,0547 \\
\hline Zonguldak & 2019 & 0,0696 & 0,1276 & 0,0790 & 0,0771 & 0,0842 \\
\hline
\end{tabular}


Yararlı bilginin ölçüsünün tespit edilmesi hedefiyle ilerleyenEntropi tekniğinde öncelikle fayda ve maliyet durumları ele alınarak karar dizeyinin normalize duruma getirilmiş hali Tablo 2.'de gösterilmiştir.

Karadeniz Bölgesi'nde yer alan 16 şehrin bankacılık verileri 2014, 2015, 2016, 2017, 2018 ve 2019 senelerine ait normalizasyon işlemi yapılmış karar dizeyinin doğal logaritması vasıtasıyla önceliklendirilmesi $\left(P_{i j} x \ln P_{i j}\right)$ aşağıda Tablo 3.'de yer almaktadır.

Tablo 3. Normalize Hale Getirilmiş Karar Dizeyinin Doğal Logaritması vasıtasıyla Önceliklendirilmesi

\begin{tabular}{|c|c|c|c|c|c|c|}
\hline İl & Yillar & Toplam Kredi & $\begin{array}{l}\text { Toplam } \\
\text { Mevduat }\end{array}$ & $\begin{array}{l}\text { Çalışan } \\
\text { Sayısı }\end{array}$ & $\begin{array}{l}\text { Şube } \\
\text { Sayısı }\end{array}$ & $\begin{array}{l}\text { Takipteki } \\
\text { Krediler Oranı }\end{array}$ \\
\hline Amasya & 2014 & $-0,149$ & $-0,122$ & $-0,132$ & $-0,143$ & $-0,160$ \\
\hline Artvin & 2014 & $-0,091$ & $-0,086$ & $-0,103$ & $-0,129$ & $-0,158$ \\
\hline Bartın & 2014 & $-0,086$ & $-0,119$ & $-0,087$ & $-0,093$ & $-0,200$ \\
\hline Çankırı & 2014 & $-0,090$ & $-0,078$ & $-0,085$ & $-0,104$ & $-0,118$ \\
\hline Çorum & 2014 & $-0,201$ & $-0,188$ & $-0,181$ & $-0,193$ & $-0,169$ \\
\hline Giresun & 2014 & $-0,154$ & $-0,176$ & $-0,152$ & $-0,164$ & $-0,206$ \\
\hline Gümüşhane & 2014 & $-0,056$ & $-0,050$ & $-0,061$ & $-0,083$ & $-0,157$ \\
\hline Karabük & 2014 & $-0,144$ & $-0,116$ & $-0,112$ & $-0,118$ & $-0,136$ \\
\hline Kastomonu & 2014 & $-0,144$ & $-0,134$ & $-0,154$ & $-0,170$ & $-0,192$ \\
\hline Ordu & 2014 & $-0,205$ & $-0,193$ & $-0,190$ & $-0,200$ & $-0,167$ \\
\hline Rize & 2014 & $-0,162$ & $-0,133$ & $-0,141$ & $-0,166$ & $-0,114$ \\
\hline Samsun & 2014 & $-0,321$ & $-0,312$ & $-0,342$ & $-0,293$ & $-0,184$ \\
\hline Sinop & 2014 & $-0,097$ & $-0,113$ & $-0,091$ & $-0,107$ & $-0,156$ \\
\hline Tokat & 2014 & $-0,180$ & $-0,139$ & $-0,168$ & $-0,191$ & $-0,216$ \\
\hline Trabzon & 2014 & $-0,268$ & $-0,274$ & $-0,279$ & $-0,264$ & $-0,155$ \\
\hline Zonguldak & 2014 & $-0,200$ & $-0,279$ & $-0,207$ & $-0,200$ & $-0,240$ \\
\hline Amasya & 2015 & $-0,151$ & $-0,119$ & $-0,134$ & $-0,147$ & $-0,163$ \\
\hline Artvin & 2015 & $-0,091$ & $-0,090$ & $-0,102$ & $-0,125$ & $-0,147$ \\
\hline Bartın & 2015 & $-0,086$ & $-0,115$ & $-0,087$ & $-0,092$ & $-0,200$ \\
\hline Çankırı & 2015 & $-0,093$ & $-0,075$ & $-0,087$ & $-0,106$ & $-0,116$ \\
\hline Çorum & 2015 & $-0,210$ & $-0,183$ & $-0,181$ & $-0,192$ & $-0,164$ \\
\hline Giresun & 2015 & $-0,157$ & $-0,175$ & $-0,153$ & $-0,166$ & $-0,197$ \\
\hline Gümüşhane & 2015 & $-0,057$ & $-0,052$ & $-0,059$ & $-0,079$ & $-0,113$ \\
\hline Karabük & 2015 & $-0,148$ & $-0,120$ & $-0,110$ & $-0,112$ & $-0,142$ \\
\hline Kastomonu & 2015 & $-0,147$ & $-0,137$ & $-0,157$ & $-0,173$ & $-0,179$ \\
\hline Ordu & 2015 & $-0,202$ & $-0,197$ & $-0,193$ & $-0,201$ & $-0,174$ \\
\hline Rize & 2015 & $-0,160$ & $-0,134$ & $-0,138$ & $-0,166$ & $-0,141$ \\
\hline Samsun & 2015 & $-0,318$ & $-0,310$ & $-0,341$ & $-0,293$ & $-0,201$ \\
\hline Sinop & 2015 & $-0,093$ & $-0,110$ & $-0,093$ & $-0,109$ & $-0,150$ \\
\hline Tokat & 2015 & $-0,179$ & $-0,140$ & $-0,168$ & $-0,193$ & $-0,221$ \\
\hline Trabzon & 2015 & $-0,265$ & $-0,283$ & $-0,277$ & $-0,264$ & $-0,176$ \\
\hline Zonguldak & 2015 & $-0,198$ & $-0,273$ & $-0,206$ & $-0,199$ & $-0,238$ \\
\hline Amasya & 2016 & $-0,1466$ & $-0,1216$ & $-0,1314$ & $-0,1445$ & $-0,1922$ \\
\hline Artvin & 2016 & $-0,0900$ & $-0,0896$ & $-0,1017$ & $-0,1272$ & $-0,1662$ \\
\hline Bartın & 2016 & $-0,0837$ & $-0,1165$ & $-0,0857$ & $-0,0903$ & $-0,1948$ \\
\hline Çankırı & 2016 & $-0,0983$ & $-0,0745$ & $-0,0850$ & $-0,1082$ & $-0,1196$ \\
\hline Çorum & 2016 & $-0,2108$ & $-0,1801$ & $-0,1800$ & $-0,1870$ & $-0,1765$ \\
\hline
\end{tabular}


Arif Çilek - Alper Karavardar

\begin{tabular}{|c|c|c|c|c|c|c|}
\hline Giresun & 2016 & $-0,1612$ & $-0,1773$ & $-0,1519$ & $-0,1690$ & $-0,1685$ \\
\hline Gümüşhane & 2016 & $-0,0574$ & $-0,0521$ & $-0,0560$ & $-0,0806$ & $-0,1088$ \\
\hline Karabük & 2016 & $-0,1466$ & $-0,1120$ & $-0,1106$ & $-0,1138$ & $-0,1334$ \\
\hline Kastomonu & 2016 & $-0,1446$ & $-0,1323$ & $-0,1545$ & $-0,1732$ & $-0,1662$ \\
\hline Ordu & 2016 & $-0,2049$ & $-0,1953$ & $-0,1940$ & $-0,1981$ & $-0,1571$ \\
\hline Rize & 2016 & $-0,1713$ & $-0,1379$ & $-0,1380$ & $-0,1648$ & $-0,1302$ \\
\hline Samsun & 2016 & $-0,3148$ & $-0,3127$ & $-0,3441$ & $-0,2966$ & $-0,2203$ \\
\hline Sinop & 2016 & $-0,0902$ & $-0,1110$ & $-0,0942$ & $-0,1110$ & $-0,1717$ \\
\hline Tokat & 2016 & $-0,1735$ & $-0,1423$ & $-0,1645$ & $-0,1908$ & $-0,2201$ \\
\hline Trabzon & 2016 & $-0,2704$ & $-0,2855$ & $-0,2776$ & $-0,2635$ & $-0,1650$ \\
\hline Zonguldak & 2016 & $-0,1914$ & $-0,2683$ & $-0,2047$ & $-0,1981$ & $-0,2319$ \\
\hline Amasya & 2017 & $-0,1438$ & $-0,1212$ & $-0,1319$ & $-0,1425$ & $-0,2048$ \\
\hline Artvin & 2017 & $-0,0907$ & $-0,0877$ & $-0,1020$ & $-0,1298$ & $-0,1734$ \\
\hline Bartın & 2017 & $-0,0859$ & $-0,1137$ & $-0,0832$ & $-0,0922$ & $-0,2051$ \\
\hline Çankırı & 2017 & $-0,1033$ & $-0,0722$ & $-0,0850$ & $-0,1105$ & $-0,1259$ \\
\hline Çorum & 2017 & $-0,2105$ & $-0,1747$ & $-0,1801$ & $-0,1865$ & $-0,1790$ \\
\hline Giresun & 2017 & $-0,1606$ & $-0,1737$ & $-0,1516$ & $-0,1722$ & $-0,1654$ \\
\hline Gümüşhane & 2017 & $-0,0569$ & $-0,0526$ & $-0,0558$ & $-0,0824$ & $-0,1055$ \\
\hline Karabük & 2017 & $-0,1273$ & $-0,1342$ & $-0,1110$ & $-0,1105$ & $-0,1439$ \\
\hline Kastomonu & 2017 & $-0,1456$ & $-0,1308$ & $-0,1528$ & $-0,1701$ & $-0,1597$ \\
\hline Ordu & 2017 & $-0,2089$ & $-0,1969$ & $-0,1945$ & $-0,1999$ & $-0,1470$ \\
\hline Rize & 2017 & $-0,1661$ & $-0,1423$ & $-0,1399$ & $-0,1658$ & $-0,1280$ \\
\hline Samsun & 2017 & $-0,3200$ & $-0,3134$ & $-0,3464$ & $-0,2967$ & $-0,2085$ \\
\hline Sinop & 2017 & $-0,0917$ & $-0,1105$ & $-0,0929$ & $-0,1134$ & $-0,1784$ \\
\hline Tokat & 2017 & $-0,1707$ & $-0,1400$ & $-0,1643$ & $-0,1826$ & $-0,2143$ \\
\hline Trabzon & 2017 & $-0,2708$ & $-0,2846$ & $-0,2749$ & $-0,2637$ & $-0,1597$ \\
\hline Zonguldak & 2017 & $-0,1919$ & $-0,2653$ & $-0,2012$ & $-0,1999$ & $-0,2269$ \\
\hline Amasya & 2018 & $-0,1408$ & $-0,1175$ & $-0,1315$ & $-0,1443$ & $-0,2072$ \\
\hline Artvin & 2018 & $-0,0903$ & $-0,0863$ & $-0,1047$ & $-0,1292$ & $-0,1750$ \\
\hline Bartın & 2018 & $-0,0865$ & $-0,1153$ & $-0,0843$ & $-0,0917$ & $-0,1833$ \\
\hline Çankırı & 2018 & $-0,1147$ & $-0,0715$ & $-0,0874$ & $-0,1128$ & $-0,1451$ \\
\hline Çorum & 2018 & $-0,2135$ & $-0,1782$ & $-0,1823$ & $-0,1877$ & $-0,1883$ \\
\hline Giresun & 2018 & $-0,1651$ & $-0,1758$ & $-0,1557$ & $-0,1735$ & $-0,1880$ \\
\hline Gümüşhane & 2018 & $-0,0583$ & $-0,0521$ & $-0,0597$ & $-0,0853$ & $-0,1033$ \\
\hline Karabük & 2018 & $-0,1298$ & $-0,1215$ & $-0,1079$ & $-0,1099$ & $-0,1375$ \\
\hline Kastomonu & 2018 & $-0,1471$ & $-0,1301$ & $-0,1545$ & $-0,1693$ & $-0,1560$ \\
\hline Ordu & 2018 & $-0,2068$ & $-0,2008$ & $-0,1942$ & $-0,2008$ & $-0,1547$ \\
\hline Rize & 2018 & $-0,1735$ & $-0,1353$ & $-0,1391$ & $-0,1628$ & $-0,1206$ \\
\hline Samsun & 2018 & $-0,3121$ & $-0,3104$ & $-0,3440$ & $-0,2967$ & $-0,2044$ \\
\hline Sinop & 2018 & $-0,0934$ & $-0,1143$ & $-0,0955$ & $-0,1184$ & $-0,1626$ \\
\hline Tokat & 2018 & $-0,1684$ & $-0,1387$ & $-0,1656$ & $-0,1817$ & $-0,2106$ \\
\hline Trabzon & 2018 & $-0,2737$ & $-0,2893$ & $-0,2741$ & $-0,2615$ & $-0,1630$ \\
\hline Zonguldak & 2018 & $-0,1871$ & $-0,2689$ & $-0,2003$ & $-0,1972$ & $-0,2285$ \\
\hline Amasya & 2019 & $-0,1392$ & $-0,1181$ & $-0,1320$ & $-0,1412$ & $-0,1864$ \\
\hline Artvin & 2019 & $-0,0902$ & $-0,0866$ & $-0,1028$ & $-0,1282$ & $-0,1814$ \\
\hline Bartın & 2019 & $-0,0826$ & $-0,1150$ & $-0,0835$ & $-0,0930$ & $-0,2224$ \\
\hline Çankırı & 2019 & $-0,1184$ & $-0,0765$ & $-0,0885$ & $-0,1143$ & $-0,1482$ \\
\hline Çorum & 2019 & $-0,2074$ & $-0,1775$ & $-0,1804$ & $-0,1879$ & $-0,1840$ \\
\hline Giresun & 2019 & $-0,1618$ & $-0,1752$ & $-0,1552$ & $-0,1736$ & $-0,1821$ \\
\hline Gümüşhane & 2019 & $-0,0576$ & $-0,0485$ & $-0,0592$ & $-0,0865$ & $-0,1465$ \\
\hline Karabük & 2019 & $-0,1303$ & $-0,1164$ & $-0,1070$ & $-0,1085$ & $-0,1448$ \\
\hline Kastomonu & 2019 & $-0,1426$ & $-0,1328$ & $-0,1563$ & $-0,1692$ & $-0,1530$ \\
\hline Ordu & 2019 & $-0,2090$ & $-0,2035$ & $-0,1966$ & $-0,2032$ & $-0,1642$ \\
\hline Rize & 2019 & $-0,1896$ & $-0,1449$ & $-0,1394$ & $-0,1626$ & $-0,1168$ \\
\hline
\end{tabular}




\begin{tabular}{lllllll} 
Samsun & 2019 & $-0,3126$ & $-0,3115$ & $-0,3427$ & $-0,2944$ & $-0,1912$ \\
Sinop & 2019 & $-0,0946$ & $-0,1119$ & $-0,0958$ & $-0,1200$ & $-0,1587$ \\
Tokat & 2019 & $-0,1685$ & $-0,1399$ & $-0,1651$ & $-0,1819$ & $-0,1970$ \\
Trabzon & 2019 & $-0,2713$ & $-0,2888$ & $-0,2768$ & $-0,2628$ & $-0,1589$ \\
Zonguldak & 2019 & $-0,1854$ & $-0,2627$ & $-0,2005$ & $-0,1976$ & $-0,2083$ \\
\hline
\end{tabular}

Tablo 3.'de $E_{j}$ ölçüsünün ve k ölçüsünün hesaplanması amacıyla Tablo 3'teki ayrı ayrı her faktör ölçüsünün $\left(P_{i j}\right)$, doğal logaritması elde edilmiş $\left(\ln _{i j}\right)$ ve bulunan logaritma ölçüsü ile kendi ölçüsü çarpma işlemine tabi tutulmuştur.

Tablo 3'te ulaşılan ölçümlerin toplamları elde edilerek $E_{j}$ ölçüsü (4) sayılı eşitlikten faydalanılarak elde edilmiştir. Sonraki adımda, (5) sayılı eşitlik vasıtasıyla ayrı ayrı her $E_{j}$ ölçüsü, 1 'den çıkarma işlemine tabi tutlarak $d_{i j} \quad$ belirsizliğine ulaşılmıştır. En son basamağa gelindiğinde, $\mathrm{j}$ kıstasının ehemmiyetinin ölçüsünün tespit edilmesi amacıyla $w_{j}$ öncelik ölçüleri elde edilmiştir.. Son üç adımda ulaşılan 2014, 2015, 2016, 2017, 2018 ve 2019 senelerine ait $E_{j}, d_{j}$ ve $w_{j}$ ölçüleri aşağıda Tablo 4.'te yer almaktadır.

Tablo 4. Ej, dj ve wj Ölçüleri

\begin{tabular}{|c|c|c|c|c|c|c|}
\hline Yillar & Değerler & $\begin{array}{l}\text { Toplam } \\
\text { Kredi }\end{array}$ & $\begin{array}{l}\text { Toplam } \\
\text { Mevduat }\end{array}$ & $\begin{array}{l}\text { Çalışan } \\
\text { Sayısı }\end{array}$ & $\begin{array}{l}\text { Şube } \\
\text { Sayısı }\end{array}$ & $\begin{array}{l}\text { Takipteki } \\
\text { Krediler Oranı }\end{array}$ \\
\hline \multirow{3}{*}{2014} & $\mathrm{Ej}$ & 0,918 & 0,906 & 0,895 & 0,945 & 0,983 \\
\hline & $\mathrm{dj}$ & 0,082 & 0,094 & 0,105 & 0,055 & 0,017 \\
\hline & wj & 0,232 & 0,267 & 0,297 & 0,157 & 0,047 \\
\hline \multirow{3}{*}{2015} & $\mathrm{Ej}$ & 0,921 & 0,906 & 0,897 & 0,944 & 0,982 \\
\hline & $\mathrm{dj}$ & 0,079 & 0,094 & 0,103 & 0,056 & 0,018 \\
\hline & wj & 0,226 & 0,269 & 0,295 & 0,160 & 0,051 \\
\hline \multirow{3}{*}{2016} & $\mathrm{Ej}$ & 0,922 & 0,905 & 0,892 & 0,944 & 0,982 \\
\hline & $\mathrm{dj}$ & 0,078 & 0,095 & 0,108 & 0,056 & 0,018 \\
\hline & wj & 0,220 & 0,267 & 0,303 & 0,158 & 0,051 \\
\hline \multirow{3}{*}{2017} & $\mathrm{Ej}$ & 0,918 & 0,907 & 0,890 & 0,944 & 0,983 \\
\hline & $\mathrm{dj}$ & 0,082 & 0,093 & 0,110 & 0,056 & 0,017 \\
\hline & wj & 0,229 & 0,261 & 0,307 & 0,155 & 0,048 \\
\hline \multirow{3}{*}{2018} & $\mathrm{Ej}$ & 0,924 & 0,904 & 0,895 & 0,946 & 0,984 \\
\hline & $\mathrm{dj}$ & 0,076 & 0,096 & 0,105 & 0,054 & 0,016 \\
\hline & wj & 0,219 & 0,277 & 0,303 & 0,155 & 0,046 \\
\hline \multirow{3}{*}{2019} & $\mathrm{Ej}$ & 0,924 & 0,905 & 0,895 & 0,947 & 0,990 \\
\hline & $\mathrm{dj}$ & 0,076 & 0,095 & 0,105 & 0,053 & 0,010 \\
\hline & wj & 0,225 & 0,279 & 0,309 & 0,157 & 0,030 \\
\hline
\end{tabular}


Tablo 5. İtibariyle WASPAS yöntemi ile Karadeniz Bölgesi'nde yer alan 16 şehrin bankacılık performans başarımlarının analizi gerçekleştirilecektir. WASPAS tekniğinin ilk adımında, Entropi tekniğinde de gerçekleştirildiği gibi karar dizeyinin meydana getirilmesi ve oluşturulan dizeyin normalize duruma getirilmesini ihtiva etmektedir. WASPAS tekniğinde meydana getirilen karar dizeyi üstünde ayrı ayrı her fayda faktörü için eşitlik (8)'den, buna ragmen ayrı ayrı her maliyet faktörü için eşitlik (9)'dan yararlanılarak normalizyon hesaplamaları gerçekleştirilmiştir. Krediler toplamı ve mevduat toplamı değerlerinden bankacilık sektörünün yara elde ettiği, buna rağmen çalışan sayısı, şube sayısı ve takipteki krediler oranının maliyet faktörü olduğu varsayılmıştır. Karadeniz Bölgesi'nde yer alan şehirlerin 2014 yılına ilişkin normalizyon işlemine tabi tutulmuş karar dizeyi aşağıda Tablo 5.'de gösterilmektedir.

Tablo 5. 2014 Yılı Waspas Tekniği ile Normalize Duruma Getirilmiş Karar Dizeyi

\begin{tabular}{llllll}
\hline \multirow{2}{*}{ Il } & \multirow{2}{*}{ Toplam Kredi } & \multirow{2}{*}{ Toplam Mevduat } & $\begin{array}{l}\text { Çalsşan } \\
\text { Sayıs }\end{array}$ & $\begin{array}{l}\text { Şube } \\
\text { Sayısı }\end{array}$ & $\begin{array}{l}\text { Takipteki Krediler } \\
\text { Oran1 }\end{array}$ \\
\hline Amasya & 0,251 & 0,201 & 0,343 & 0,463 & 0,608 \\
Artvin & 0,124 & 0,123 & 0,492 & 0,543 & 0,622 \\
Bartın & 0,115 & 0,193 & 0,619 & 0,864 & 0,429 \\
Çankırı & 0,122 & 0,107 & 0,639 & 0,731 & 0,959 \\
Çorum & 0,400 & 0,385 & 0,214 & 0,292 & 0,562 \\
Giresun & 0,263 & 0,347 & 0,280 & 0,380 & 0,408 \\
Gümüşhane & 0,064 & 0,061 & 1,000 & 1,000 & 0,625 \\
Karabük & 0,238 & 0,187 & 0,436 & 0,613 & 0,780 \\
Kastomonu & 0,238 & 0,228 & 0,275 & 0,358 & 0,458 \\
Ordu & 0,415 & 0,402 & 0,198 & 0,275 & 0,568 \\
Rize & 0,283 & 0,226 & 0,313 & 0,373 & 1,000 \\
Samsun & 1,000 & 1,000 & 0,060 & 0,136 & 0,491 \\
Sinop & 0,135 & 0,178 & 0,581 & 0,704 & 0,632 \\
Tokat & 0,334 & 0,241 & 0,240 & 0,297 & 0,376 \\
Trabzon & 0,670 & 0,747 & 0,100 & 0,168 & 0,639 \\
Zonguldak & 0,396 & 0,775 & 0,172 & 0,275 & 0,313 \\
\hline
\end{tabular}

İkici basamakta (10) sayılı eşitlik vasıtasıyla Ağırlıklı Toplam Modeline (WSM) dair bağıl ehemmiyetinin bulunması amacıyla, normalize duruma getirilmiş karar dizeyi üstünden ayrı ayrı her $i$ seçeneğin ölçüsü Entropi tekniğinin sonuncu adımında ulaşılan ilgili faktör ağırlık ölçüsüyle çarpılmış ve ayrı ayrı her şehre göre toplanarak Tablo 6.'da bulunan $\mathrm{Q}_{i}{ }^{(1)}$ ölçülerine ulaşılmıştır. Karadeniz Bölgesi'nde 
yer alan 16 şehrin 2014 senesine ait ağırlıklı toplam modeline (WSM) göre toplam bağıl önem ölçüleri aşağıda Tablo 6.'da yer almaktadır. Tablo 6. 2014 Yılı WSM'ye Dayalı Toplam Görece Önem Değerleri

\begin{tabular}{lllllll}
\hline Il & $\begin{array}{l}\text { Toplam } \\
\text { Kredi }\end{array}$ & $\begin{array}{l}\text { Toplam } \\
\text { Mevduat }\end{array}$ & $\begin{array}{l}\text { Çalışan } \\
\text { Sayısı }\end{array}$ & $\begin{array}{l}\text { Şube } \\
\text { Sayıs }\end{array}$ & $\begin{array}{l}\text { Takipteki } \\
\text { Krediler Oranı }\end{array}$ & $\mathbf{Q}^{(1)}$ \\
\hline Amasya & 0,058 & 0,054 & 0,102 & 0,073 & 0,029 & 0,315 \\
Artvin & 0,029 & 0,033 & 0,146 & 0,085 & 0,030 & 0,323 \\
Bartın & 0,027 & 0,051 & 0,184 & 0,135 & 0,020 & 0,418 \\
Çankırı & 0,028 & 0,029 & 0,190 & 0,115 & 0,045 & 0,407 \\
Çorum & 0,093 & 0,103 & 0,063 & 0,046 & 0,027 & 0,331 \\
Giresun & 0,061 & 0,093 & 0,083 & 0,060 & 0,019 & 0,316 \\
Gümüşhane & 0,015 & 0,016 & 0,297 & 0,157 & 0,030 & 0,515 \\
Karabük & 0,055 & 0,050 & 0,130 & 0,096 & 0,037 & 0,368 \\
Kastomonu & 0,055 & 0,061 & 0,082 & 0,056 & 0,022 & 0,275 \\
Ordu & 0,096 & 0,107 & 0,059 & 0,043 & 0,027 & 0,332 \\
Rize & 0,066 & 0,060 & 0,093 & 0,058 & 0,047 & 0,325 \\
Samsun & 0,232 & 0,267 & 0,018 & 0,021 & 0,023 & 0,561 \\
Sinop & 0,031 & 0,048 & 0,173 & 0,110 & 0,030 & 0,392 \\
Tokat & 0,077 & 0,064 & 0,071 & 0,047 & 0,018 & 0,277 \\
Trabzon & 0,155 & 0,199 & 0,030 & 0,026 & 0,030 & 0,441 \\
Zonguldak & 0,092 & 0,207 & 0,051 & 0,043 & 0,015 & 0,408 \\
\hline
\end{tabular}

Bir sonraki adımada (11) sayılı eşitlik vasıtasıyla, Ağırlıklı Çarpım Modeline (WPM) göre $i$ seçeneğinin toplam bağıl değerinin bulunması hedefiyle, yine normalizyon işlemine tabi tutulmuş karar dizeyi üstünden ayrı ayrı her $i$ seçenek ölçüsü için ilgili faktör ağırlı̆̆ının matematiksel olarak üssü işlemi yapılmış ve ulaşılan ölçüler ayrı ayrı her seçenek için sırayla çarpılarak Tablo 7.'de bulunan $\mathrm{Q}_{i}{ }^{(2)}$ ölçümlerine ulaşılmıştır. Karadeniz bölgesinde yer alan şehrin bankacılık performansının 2014 senesine ait ağırlıklı çarpım modeline (WPM) göre toplam bağıl önem ölçüleri aşağıda Tablo 7.'de yer almaktadır.

Tablo 7. 2014 Yılı WPM'ye Dayalı Toplam Görece Önem Değerleri

\begin{tabular}{lllllll}
\hline İl & $\begin{array}{l}\text { Toplam } \\
\text { Kredi }\end{array}$ & $\begin{array}{l}\text { Toplam } \\
\text { Mevduat }\end{array}$ & $\begin{array}{l}\text { Çalışan } \\
\text { Sayıs }\end{array}$ & $\begin{array}{l}\text { Şube } \\
\text { Sayıs }\end{array}$ & $\begin{array}{l}\text { Takipteki } \\
\text { Krediler Oranı }\end{array}$ & $\mathbf{Q}^{(2)}$ \\
\hline Amasya & 0,726 & 0,651 & 0,728 & 0,886 & 0,977 & 0,298 \\
Artvin & 0,616 & 0,572 & 0,810 & 0,909 & 0,978 & 0,254 \\
Bartın & 0,606 & 0,644 & 0,867 & 0,977 & 0,961 & 0,318 \\
Çankırı & 0,614 & 0,551 & 0,875 & 0,952 & 0,998 & 0,282 \\
Çorum & 0,809 & 0,775 & 0,632 & 0,825 & 0,973 & 0,318 \\
Giresun & 0,734 & 0,754 & 0,685 & 0,859 & 0,958 & 0,312 \\
Gümüşhane & 0,529 & 0,473 & 1,000 & 1,000 & 0,978 & 0,245
\end{tabular}




\begin{tabular}{lllllll} 
Karabük & 0,717 & 0,639 & 0,781 & 0,926 & 0,988 & 0,328 \\
Kastomonu & 0,717 & 0,674 & 0,681 & 0,851 & 0,964 & 0,270 \\
Ordu & 0,816 & 0,784 & 0,617 & 0,817 & 0,974 & 0,314 \\
Rize & 0,747 & 0,673 & 0,708 & 0,857 & 1,000 & 0,305 \\
Samsun & 1,000 & 1,000 & 0,433 & 0,731 & 0,967 & 0,306 \\
Sinop & 0,629 & 0,631 & 0,851 & 0,946 & 0,978 & 0,313 \\
Tokat & 0,775 & 0,684 & 0,654 & 0,827 & 0,955 & 0,274 \\
Trabzon & 0,911 & 0,925 & 0,504 & 0,756 & 0,979 & 0,314 \\
Zonguldak & 0,807 & 0,934 & 0,592 & 0,817 & 0,946 & 0,345 \\
\hline
\end{tabular}

WSM ve WPM modeline göre $\mathrm{Q}_{i}^{(1)}$ ve $\mathrm{Q}_{i}^{(2)}$ ölçümleri elde edildikten sonra (12) sayılı eşitlik vasıtasıyla Ağırlıklandırılmış Ortak Genel Kıstas Ölçüsü $\mathrm{Q}_{i}{ }^{\prime}$ ye ulaşılmış, arkasından sıralama gerçekleştirilmiştir. Ulaşılan $\mathrm{Q}_{i}$ ölçüleri ve gerçekleştirilen siralama ölçüleri Tablo 8.'de bulunmaktadır. Karadeniz Bölgesi'nde yer alan 16 şehrin bankacılık performansının 2014 senesine ait önceliklendirilmiş ortak genel kıstas ölçüleri ve sıralama ölçüleri aşığıda Tablo 8.'de gösterilmiştir.

Tablo 8. 2014 Yılı Ă̆ırlıklandırılmış Ortak Kriter Değerleri

\begin{tabular}{llll}
\hline il & $\mathbf{Q}_{i}$ & Siralama & En İyi Performans \\
\hline Amasya & 0,307 & 13 & \\
Artvin & 0,288 & 14 & \\
Bartın & 0,368 & 5 & \\
Çankırı & 0,344 & 8 & \\
Çorum & 0,325 & 9 & \\
Giresun & 0,314 & 12 & \\
Gümüşhane & 0,380 & 2 & \\
Karabük & 0,348 & 7 & \\
Kastomonu & 0,273 & 16 & \\
Ordu & 0,323 & 10 & \\
Rize & 0,315 & 11 & \\
Samsun & 0,433 & $\mathbf{1}$ & \\
Sinop & 0,352 & 6 & \\
Tokat & 0,276 & 15 & \\
Trabzon & 0,378 & 3 & \\
Zonguldak & 0,377 & 4 & \\
\hline
\end{tabular}

Tablo 8.'de elde edilen siralama değerlerine göre 2014 yılında en iyi bankacılık performansına sahip şehir Samsun olurken bunu sırasıyla Gümüşhane, Trabzon ve Zonguldak takip etmiştir. 2014 yılında diğer şehirlere göre daha düşük performans sergileyerek listenin son 
basamağında yer alan şehir Kastamonu olurken Tokat sondan ikinci olarak tabloda kendine yer bulmuştur.

Karadeniz Bölgesi'nde yer alan şehirlerin bankacılık performans sıralamasını oluşturmak amacıyla 2014 yılının karar matrisine uygulanan WASPAS yöntemi uygulama aşamaları diğer yılların karar matrislerine de uygulanarak yıllara göre sıralama değerleri elde edilmiş ve yıllara göre bulunan sıralamalar aşağıdaki Tablo 9.'da verilmiştir.

Yıllara göre elde edilen Karadeniz Bölgesi'ndeki şehirlerin bankacılık performans sıralamasına bakıldığında Samsun 2014-2019 döneminde birinci sırada yer almıştır. Gümüşhane 2014-2017 yıllarında ikici sırada yer alırken, 2018 ve 2019 yıllarında üçünçü sıraya gerilemiştir.

Tablo 9. Yıllara Göre WASPAS Performans Karşılaştırması

\begin{tabular}{lllllll}
\hline İl & $\mathbf{2 0 1 4}$ & $\mathbf{2 0 1 5}$ & $\mathbf{2 0 1 6}$ & $\mathbf{2 0 1 7}$ & $\mathbf{2 0 1 8}$ & $\mathbf{2 0 1 9}$ \\
\hline Amasya & 13 & 13 & 13 & 13 & 13 & 13 \\
Artvin & 14 & 14 & 14 & 14 & 14 & 14 \\
Bartın & 5 & 5 & 4 & 4 & 4 & 4 \\
Çankırı & 8 & 8 & 7 & 7 & 7 & 8 \\
Çorum & 9 & 9 & 9 & 10 & 10 & 11 \\
Giresun & 12 & 11 & 11 & 12 & 12 & 12 \\
Gümüşhane & 2 & 2 & 2 & 2 & 3 & 3 \\
Karabük & 7 & 6 & 6 & 6 & 6 & 6 \\
Kastomonu & 16 & 15 & 16 & 15 & 15 & 16 \\
Ordu & 10 & 10 & 10 & 9 & 9 & 9 \\
Rize & 11 & 12 & 12 & 11 & 11 & 7 \\
Samsun & $\mathbf{1}$ & $\mathbf{1}$ & $\mathbf{1}$ & $\mathbf{1}$ & $\mathbf{1}$ & $\mathbf{1}$ \\
Sinop & 6 & 7 & 8 & 8 & 8 & 10 \\
Tokat & 15 & 16 & 15 & 16 & 16 & 15 \\
Trabzon & 3 & 3 & 3 & 3 & 2 & 2 \\
Zonguldak & 4 & 4 & 5 & 5 & 5 & 5 \\
\hline
\end{tabular}

2014-2017 yıllarında üçüncü sırada yer alan Trabzon ise 2018 ve 2019 yıllarında ikinciliği elde etmiştir. Kastamonu 2014, 2016 ve 2019 yıllarında son sırada yer alırken, Tokat 2015, 2017 ve 2018 yıllarında son sırada yer almıştır. Tüm yıllar boyunca sıralaması değişmeyen Amasya ve Artvin şehirleri sırasıyla onüçüncü ve ondördüncü sırada yerlerini almışlardır. Genel olarak 2014-2019 döneminde şehirlerin sıralamasında çok aşırı değişme olmamakla birlikte, Sinop'un sıralamasında gerileme, Rize'nin sıralamasında ise ilerleme görülmektedir. 


\section{Tartışma ve Sonuç}

Bu çalışmada Karadeniz Bölgesi'nde yer alan şehirlerin bankacılık performans başarımları Türkiye Bankalar Birliği internet sayfasından, temel mali tablolardan olan bilanço değerleri ve istatistiki veriler üstünden incelenerek Entropi tekniği ve WASPAS tekniği yardımıla analiz edilmiştir. Yapılan analizler vasıtasıyla 2014, 2015, 2016, 2017, 2018 ve 2019 yılları için en iyi performans başarımı gösteren şehrin Samsun olduğu, diğer taraftan en kötü performan başarımı gösteren şehirlerin Kastamonu ve Tokat olduğu bulguları elde edilmiştir. Genel olarak değerlendirildiğinde; belirtilen kriterler doğrultusunda Samsun hem kredi hem mevduat tutarı açısından bakıldığında yıl bazlı verilerinde rakamsal olarak birinci sırada olması, yani kredi ve mevduat turarlarının maksimum olması istenen bir durumda da iyi bir performans göstermiştir.

Karadeniz Bölgesi'nde yer alan 16 şehrin bankacıllk performans başarım sıralamasının tercih edilen kıstaslar bakımından ortaya koyulduğu, kıstaslar ve analize tabi tutulan dönemler farklılaştığında başarı sıralamasınında değişebileceği göz önünde tutulmalıdır. Bundan sonrasında, Entropi ve Waspas teknikleri vasıtasıyla farklı ülkelerde ve farklı bölgelerde performans değerlendirmesi ile alakalı çalışmaların gerçekleştirilmesinin, hem alanyazına hem de bankacılık sektöründe faaliyetde bulunan tatbik edicilere bilgi temin edeceği sonucuna varılabilir.

Bundan böyle ortaya koyulacak çalışmalarda, öne sürülen bakış açısı daha fazla faktör ve tercih sayıları bakımından tekrar analiz edilebilir. Ayrıca çalışma sezgisel bulanık mantık, ENTROPI ve WASPAS tekniklerinden yararlanılarak karar vericilerin kesin bilgi edinmediği hallerde de banka performans başarımı prosesini gerçekleştirmesi temin edilebilir. 


\section{EXTENDED ABSTRACT}

\section{Analysis of the Banking Performance of Cities in the Black Sea Region with Entropy-Based Waspas Method: 2014-2019 Period}

Arif Çilek - Alper Karavardar

GiresunUniversity

Banks are of great value in terms of a country's economy, as they act as a bridge in the conversion of household savings to investment. The ability of banks to attract monetary gains and to offer direct loans and other banking services directly contributes to the development and economic growth of a country. In this context, there is a positive correlation between economic growth and bank profitability due to banks' achieving sustainable profitability, achieving sustainable growth, and its relationship with and contribution to economic growth. At the same time, banks with a sound balance sheet structure minimize fragility when negative shocks such as economic crisis occur (Sar1, 2020, p. 101).

Bank efficiency and performance results are utilized in order to understand the extent to which banks continue their activities properly, to compare banks with each other and to analyze their growth. Measuring the success of banks, which have the largest place among the players in the financial system, is important for the following reasons (Seçme, Bayrakdaroğlu \& Kahraman, 2009, p.11699).

- Making comparisons by determining their place in the banking system.

- To evaluate the performance of the bank in terms of the bank's top management and bank partners.

- To determine that decisions are made on the basis of real data rather than with the help of hypotheses or feelings.

- Identifying problematic sections in the organization and providing recommendations for eliminating these probes.

- Identifying the departments within the organization that are open to the learning organization and can gain competitive advantage. 
For the aforementioned reasons, quantitative and qualitative analysis methods used in measuring financial performance have been developed and used in evaluations. Multi Criteria Decision Making methods are suitable methods for evaluating many alternatives and criteria that exist to make comparisons in the banking sector. MCDM methods can analyze by considering the factors expressed in multiple and independent ways. Because, the ranking and comparison of regions according to the performance of banks can be handled with more than one criteria and mathematical methods that take all of these criteria into account.

Located in the Black Sea region of Turkey study is aimed to make the analysis of the performance of the banking city. In this context, firstly using Entropy technique, which is one of the multi-criteria decisionmaking techniques; Weighted the factors of total loans, total deposits, number of employees, number of branches and ratio of loans in followup accounts were calculated. Following the calculation of the weight factor of WASPAS well as technical dimensions of the Black Sea Region is located in the city of banking performance in Turkey it was determined.

Considering the banking performance ranking of the cities in the Black Sea Region obtained by years, Samsun ranked first in the period of 2014-2019. While Gümüşhane ranked second in 2014-2017, it fell to third place in 2018 and 2019. Trabzon, which ranked third in 2014-2017, ranked second in 2018 and 2019. While Kastamonu ranked last in 2014, 2016 and 2019, Tokat was in the last place in 2015, 2017 and 2018. The cities of Amasya and Artvin, whose rankings did not change throughout the years, took their places in the thirteenth and fourteenth respectively. In general, although there was not much change in the ranking of cities in the 2014-2019 period, there is a decline in the ranking of Sinop and progress in the ranking of Rize.

It should be kept in mind that the banking performance performance ranking of 16 cities in the Black Sea Region is presented in terms of preferred criteria, and the success ranking may change when the criteria and the periods subjected to analysis differ. After that, it can be concluded that conducting studies related to performance evaluation in different countries and different regions through Entropy and Waspas 
techniques will provide information to both the literature and practitioners operating in the banking sector.

Table 1. WASPAS Performance Comparison by Years

\begin{tabular}{lllllll}
\hline İl & $\mathbf{2 0 1 4}$ & $\mathbf{2 0 1 5}$ & $\mathbf{2 0 1 6}$ & $\mathbf{2 0 1 7}$ & $\mathbf{2 0 1 8}$ & $\mathbf{2 0 1 9}$ \\
\hline Amasya & 13 & 13 & 13 & 13 & 13 & 13 \\
Artvin & 14 & 14 & 14 & 14 & 14 & 14 \\
Bartın & 5 & 5 & 4 & 4 & 4 & 4 \\
Çankırı & 8 & 8 & 7 & 7 & 7 & 8 \\
Çorum & 9 & 9 & 9 & 10 & 10 & 11 \\
Giresun & 12 & 11 & 11 & 12 & 12 & 12 \\
Gümüşhane & 2 & 2 & 2 & 2 & 3 & 3 \\
Karabük & 7 & 6 & 6 & 6 & 6 & 6 \\
Kastomonu & 16 & 15 & 16 & 15 & 15 & 16 \\
Ordu & 10 & 10 & 10 & 9 & 9 & 9 \\
Rize & 11 & 12 & 12 & 11 & 11 & 7 \\
Samsun & $\mathbf{1}$ & $\mathbf{1}$ & $\mathbf{1}$ & $\mathbf{1}$ & $\mathbf{1}$ & $\mathbf{1}$ \\
Sinop & 6 & 7 & 8 & 8 & 8 & 10 \\
Tokat & 15 & 16 & 15 & 16 & 16 & 15 \\
Trabzon & 3 & 3 & 3 & 3 & 2 & 2 \\
Zonguldak & 4 & 4 & 5 & 5 & 5 & 5 \\
\hline
\end{tabular}

In the studies to be put forward from now on, the perspective put forward can be analyzed again in terms of more factors and number of preferences. In addition, by making use of heuristic fuzzy logic, ENTROPI and WASPAS techniques, it can be ensured that decision makers perform the bank performance performance process even when they do not obtain precise information.

\section{Kaynakça / References}

Akçakanat, Ö., Eren, H., Aksoy, E. ve Ömürbek, V. (2017). Bankacılık sektöründe entropi ve waspas yöntemleri ile performans değerlendirmesi. Suleyman Demirel University Journal of Faculty Of Economics \& Administrative Sciences, 22(2), 285-300.

Alinezhad, A., ve Khalili, J. (2019). WASPAS method. In New Methods and Applications in Multiple Attribute Decision Making (MADM) (pp. 9398). Springer, Cham.

Alkan, Ö. ve Albayrak, Ö. K. (2020). Ranking of renewable energy sources for regions in Turkey by fuzzy entropy based fuzzy COPRAS and fuzzy MULTIMOORA. Renewable Energy, 162, 712-726. 
Bera, A. K., ve Park, S. Y. (2008). Optimal portfolio diversification using the maximum entropy principle. Econometric Reviews, 27(4-6), 484-512.

Bostanci, S. H., ve Ocakçi, M. (2009). Kent siluetlerine ilişkin tasarım niteliklerinin, entropi yaklaşımı ile değerlendirilmesi. İstanbul Teknik Üniversitesi Dergisi, 8(2), 27-36.

Brauers, W. K. M., ve Zavadskas, E. K. (2012). Robustness of MULTIMOORA: A method for multi-objective optimization. Informatica, 23(1), 1-25.

Chakraborty, S., ve Zavadskas, E. K. (2014). Applications of WASPAS method in manufacturing decision making. Informatica, 25(1), 1-20.

Chakraborty, S., Zavadskas, E. K. ve Antucheviciene, J. (2015). Applications of WASPAS method as a multi-criteria decision-making tool. Economic Computation and Economic Cybernetics Studies and Research, 49(1), 5-22.

Eş, A. ve Kök, E. (2020). Banka performanslarının entropi tabanlı WASPAS yöntemiyle analizi. Düzce Üniversitesi Sosyal Bilimler Enstitüsü Dergisi, 10(2), 233-250.

Gezen, A. (2019). Türkiye'de faaliyet gösteren katılım bankalarının entropi ve WASPAS yöntemleri ile performans analizi. Muhasebe ve Vergi Uygulamalari Dergisi (MUVU)/Journal of Accounting $\mathcal{E}$ Taxation Studies (JATS), 84, 213-232.

Huang, X. (2012). An entropy method for diversified fuzzy portfolio selection. International Journal of Fuzzy Systems, 14(1), 160-165.

Karaca, S., Altemur, N. ve Çevik, M. (2020). Bankacılık sektöründe performans analizi: Entropi ve waspas yöntemi uygulaması. Malatya Turgut Özal Üniversitesi Işletme Ve Yönetim Bilimleri Dergisi, 1(2), 4676

Karami, A., ve Johansson, R. (2014). Utilizization of multi attribute decision making techniques to integrate automatic and manual ranking of options. Journal of information science and engineering, 30, 519-534.

Karavardar, A. ve Çilek, A. (2020). Banka tercihini belirleyen kriterlerin Entropi Yöntemi ile ağirliklandirilmasi: Giresun ili örneği. İşletme Araştırmaları Dergisi, 12(4), 3482-3492.

Madić, M., Gecevska, V., Radovanović, M., ve Petković, D. (2014). Multicriteria economic analysis of machining processes using the WASPAS method. Journal of Production Engineering, 17(2), 79-82. 
Memiş, S. (2019). Konaklama işletmelerinde yeşil yönetim uygulamalarının ENTROPI Yöntemi ile ağırlıklandırılması: Giresun ili örneği. İşletme Araştırmaları Dergisi, 11(1), 653-665.

Ömürbek, N., Karaatli, M. ve Balci, H. F. (2016). Entropi temelli Maut ve Saw yöntemleri ile otomotiv firmalarının performans değerlemesi. Dokuz Eylül Üniversitesi İktisadi İdari Bilimler Fakültesi Dergisi, 31(1), 227-255.

Qin, Z., Li, X., ve Ji, X. (2009). Portfolio selection based on fuzzy crossentropy. Journal of Computational and Applied mathematics, 228(1), 139149.

Sarı, T. (2020). Banka performans ölçümünde Topsis ve Promethee Yöntemlerinin karşılaştırılması. Ataturk University Journal of Economics \& Administrative Sciences, 34(1), 99-117.

Sarıkaya, G. ve Tatlidil, H. (2014). Entropi optimizasyon ölçüsü ile optimal portföy seçimi ve Bist Ulusal-30 endeksi üzerine bir çalışma. Dumlupınar Üniversitesi Sosyal Bilimler Dergisi, XIV. Uluslararası Ekonometri Sempozyumu Özel Sayısı, 381-402.

Seçme, N. Y., Bayrakdaroğlu, A. ve Kahraman, C. (2009). Fuzzy performance evaluation in Turkish banking sector using analytic hierarchy process and TOPSIS. Expert Systems with Applications, 36(9), 1169911709.

TBB, Türkiye Bankalar Birliği (2020). https://www.tbb.org.tr/tr/bankacilik/banka-ve-sektor-bilgileri/istatistiki-raporlar/59 (Erişim Tarihi: 15.01.2020).

Tunca, M. Z., Ömürbek, N., Cömert, H. G. ve Aksoy, E. (2016). Opec ülkelerinin performanslarinin çok kriterli karar verme yöntemlerinden Entropi ve Maut ile değerlendirilmesi. Süleyman Demirel Üniversitesi Vizyoner Dergisi, 7(14), 1-12.

Ural, M., Demireli, E., ve Güler Özçalik, S. (2018). Kamu bankalarında performans analizi: Entropi ve Waspas yöntemleri ile bir uygulama. Pamukkale University Journal of Social Sciences Institute/Pamukkale Üniversitesi Sosyal Bilimler Enstitüsü Dergisi, 31, 129-141.

Usta, I., ve Kantar, Y. M. (2011). Mean-variance-skewness-entropy measures: A multi-objective approach for portfolio selection. Entropy, 13(1), 117-133. 
Wang, T. C., ve Lee, H. D. (2009). Developing a fuzzy TOPSIS approach based on subjective weights and objective weights. Expert systems with applications, 36(5), 8980-8985.

Wu, J., Sun, J., Liang, L., ve Zha, Y. (2011). Determination of weights for ultimate cross efficiency using Shannon entropy. Expert Systems with Applications, 38(5), 5162-5165.

Zavadskas, E. K., Antucheviciene, J., Saparauskas, J., and Turskis, Z. (2013). MCDM methods WASPAS and MULTIMOORA: Verification of robustness of methods when assessing alternative solutions. Economic Computation and Economic Cybernetics Studies and Research, 47(2), 5-20.

Zavadskas, E. K., Turskis, Z., Antucheviciene, J., ve Zakarevicius, A. (2012). Optimization of weighted aggregated sum product assessment. Elektronika ir elektrotechnika, 122(6), 3-6.

Zhang, H., Gu, C. L., Gu, L. W., ve Zhang, Y. (2011). The evaluation of tourism destination competitiveness by TOPSIS \& information entropy-A case in the Yangtze River Delta of China. Tourism Management, 32(2), 443-451.

Zhang, W. G., Liu, Y. J. ve Xu, W. J. (2012). A possibilistic meansemivariance-entropy model for multi-period portfolio selection with transaction costs. European Journal of Operational Research, 222(2), 341-349.

Zhou, H., Wang, J. ve Qiu, Y. (2008). Application of the Cross Entropy Method to the credit risk assessment in an early warning system. In 2008 International Symposiums on Information Processing, 728-732.

Zhou, R., Cai, R., ve Tong, G. (2013). Applications of entropy in finance: A review. Entropy, 15(11), 4909-4931.

\section{Kaynakça Bilgisi / Citation Information}

Çilek, A. ve Karavardar, A. (2021). Entropi tabanlı Waspas Yöntemiyle Karadeniz Bölgesindeki Şehirlerin bankacılık performansının analizi: 2014-2019 dönemi. OPUS-Uluslararası Toplum Araştırmaları Dergisi, 18(Yönetim ve Organizasyon Özel Sayısı), 1484-1513. DOI: 10.26466/opus.866120. 